\title{
Facies sedimentarias turbidíticas del Terciario Inferior en la Cuenca de Chicontepec, Centro-Oriente de México
}

\author{
Lower Tertiary Sedimentary Turbidite Facies at \\ the Chicontepec Basin, East-Central Mexico
}

\author{
Santillán-Piña N. \\ División de Ingeniería en Ciencias de la Tierra \\ Facultad de Ingeniería \\ Universidad Nacional Autónoma de México \\ noesant@hotmail.com
}

\author{
Aguayo-Camargo J.E. \\ División de Ingeniería en Ciencias de la Tierra \\ Facultad de Ingeniería \\ Universidad Nacional Autónoma de México \\ aguayojec@yahoo.com.mx
}

Información del artículo: recibido: diciembre de 2009, aceptado: mayo de 2010

\section{Resumen}

El área de estudio comprende la porción noroccidental de la Cuenca de Chicontepec, en el sureste del estado de San Luis Potosí y el noreste de Hidalgo. En las secuencias estratigráficas de la Formación Chicontepec del Paleoceno Inferior, en afloramientos aislados, se interpretaron dos subambientes sedimentarios mayores en el modelo de abanico: el medio y el externo, cuyos criterios para su identificación fueron: (a) litoestratigráficos (espesor, geometría y distribución); (b) estructuras sedimentarias primarias internas y externas y (c) estructuras por deformación intraformacional. Las facies sedimentarias están compuestas por partículas siliciclásticas y calcáreas provenientes de la Sierra Madre Oriental, al occidente; la paleoisla de Tuxpan, al oriente; el macizo de Teziutlán, al sur; los sedimentos fueron transportados masivamente como deslizamientos, derrumbes, flujos de escombros y por corrientes de turbidez y depositados de forma masiva, tabular, lenticular y lobular al pie de talud de la cuenca y en el piso marino.

\footnotetext{
Abstract

The study area comprises the northwestern portion of the Chicontepec Basin at southeastern San Luis Potosí and northeastern Hidalgo States. At the stratigraphy sequences of the Chicontepec Formation from Lower Paleocene in isolated outocrops, were herein interpreted two major sedimentary sub-environments into the fan model: the middle and the external sedimentary settings; the applied criteria for their identification were: (a) lithostratigraphic (thickness, geometry and distribution); (b) internal and external primary sedimentary structures, and (c) intra-formational deformation structures. The sedimentary facies are composed of siliciclastic and calcareous particles sourced from the Sierra Madre Oriental, western; the Tuxpan paleo-island, eastern; and from the Teziutlan Massif, southern; the sediments were massively transported by slideing, slumping, flow debris and turbidity currents, then deposited as massive, tabular, lenticular and lobely in shape at the slope foot and on the sea marine floor.
}

\section{Descriptores}

- Golfo de México

- Cuenca de Chicontepec

- Paleógeno

- sistemas turbidíticos

\section{Keywords}

- Gulf of Mexico

- Chicontepec Basin

- Paleogene

- turbidite systems 


\section{Introducción}

\section{Localización}

La Cuenca de Chicontepec se sitúa en la porción centrooriente de la República Mexicana sobre la planicie costera del Golfo de México; su eje axial tiene una longitud de $250 \mathrm{~km}$, orientado NW-SE y cubre una superficie oval de $11,300 \mathrm{~km}^{2}$ con una anchura promedio de unos $60 \mathrm{~km}$. Comprende principalmente a dos Provincias Fisiográficas: la de la Llanura Costera del Golfo Norte y subprovincia de las llanuras y lomeríos, así como la de la Sierra Madre Oriental y subprovincia del Carso Huasteco (figura 1).

Los estratos paleógenos afloran en la porción occidental y sureste en la parte marginal de la Cuenca Tam-
pico-Tuxpan, principalmente en la parte norte del estado de Veracruz; aunque también se extienden en el extremo sur del estado de Tamaulipas y las porciones más orientales en los estados de San Luis Potosí, Hidalgo y norte de Puebla (figura 2).

\section{Objetivos}

Contribuir al conocimiento de las facies turbidíticas depositadas en los subambientes de los complejos sedimentarios de la cuenca terciaria de Chicontepec, en el centro-oriente de México, mediante la descripción y estudio de las secuencias estratigráficas en los afloramientos situados al noroccidente de la provincia geológica terciaria.

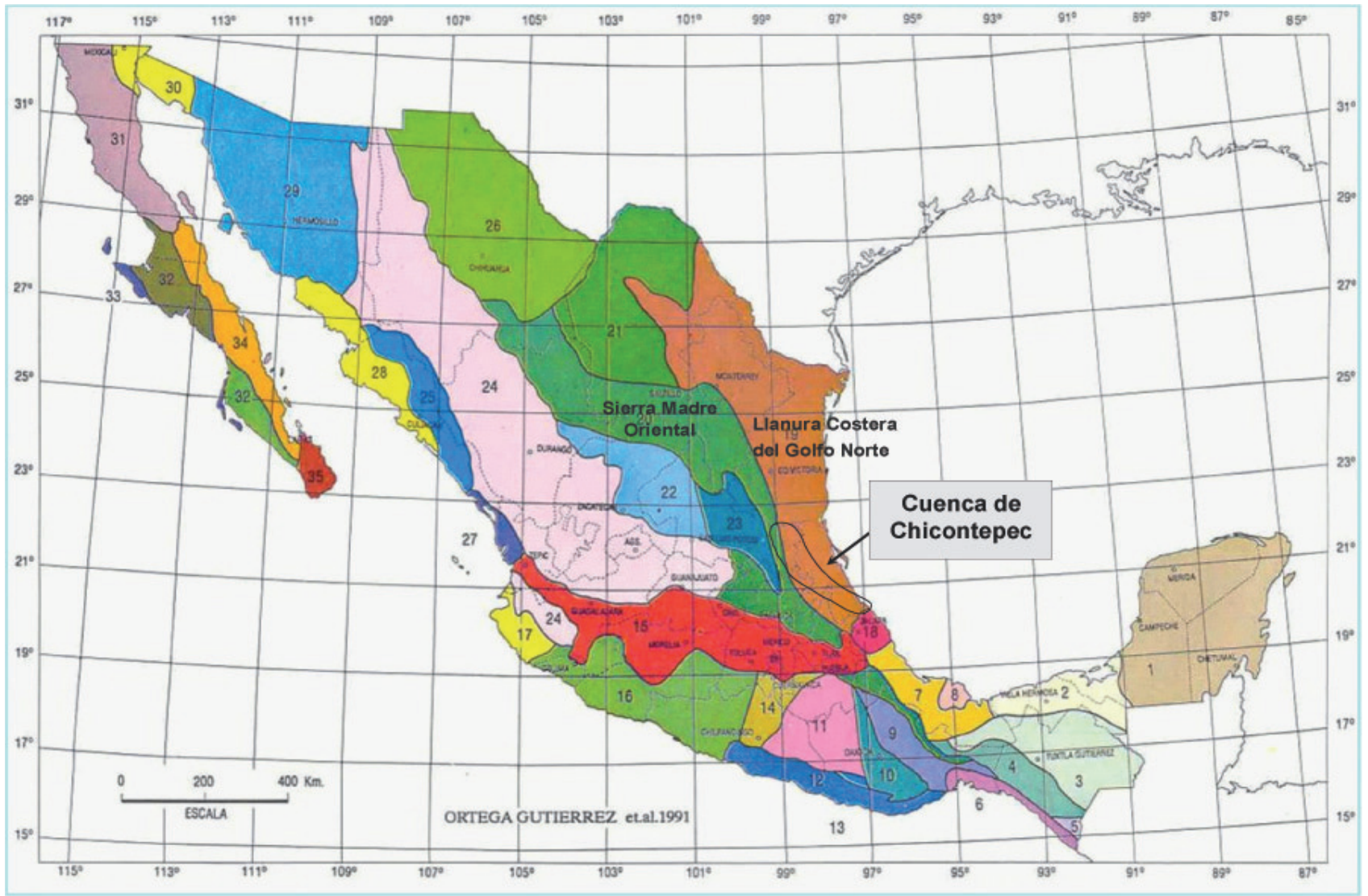

Figura 1. Provincias Geológicas de la Republica Mexicana: 1. Plataforma de Yucatán, 2. Cuenca Deltaica de Tabasco, 3. Cinturón chiapaneco de pliegues y fallas, 4. Batolito de Chiapas, 5. Macizo Ígneo del Soconusco, 6. Cuenca de Tehuantepec, 7. Cuenca Deltaica de Veracruz, 8. Macizo volcánico de los Tuxtlas, 9. Cuicateca, 10. Zapoteca, 11. Mixteca, 12. Chatina, 13. Juchateca, 14. Plataforma de Morelos, 15. Faja volcánica transmexicana, 16. Complejo Orogénico de Guerrero-Colima, 17. Batolito de Jalisco, 18. Macizo Ígneo de Palma Sola, 19. Migeoclinal del Golfo de México, 20. Cinturón mexicano de pliegues y fallas, 21. Plataforma de Coahuila, 22. Zacatecana, 23. Plataforma de Valles-San Luis Potosí, 24. Faja Ignimbrítica mexicana, 25. Cinturón Orogénico sinaloense, 26. Chihuahuense, 27. Cuenca de Nayarit, 28. Cuenca Deltaica de Sonora-Sinaloa, 29. Sonorense, 30. Delta del Colorado, 31. Batolito de Juárez-San Pedro Mártir, 32. Cuenca de Vizcaíno-Purísima, 33. Cinturón orogénico de Cedros-Margarita, 34. Faja volcánica de La Giganta, y 35. Complejo Plutónico de La Paz. Complementada de Ortega et al. (1992) 


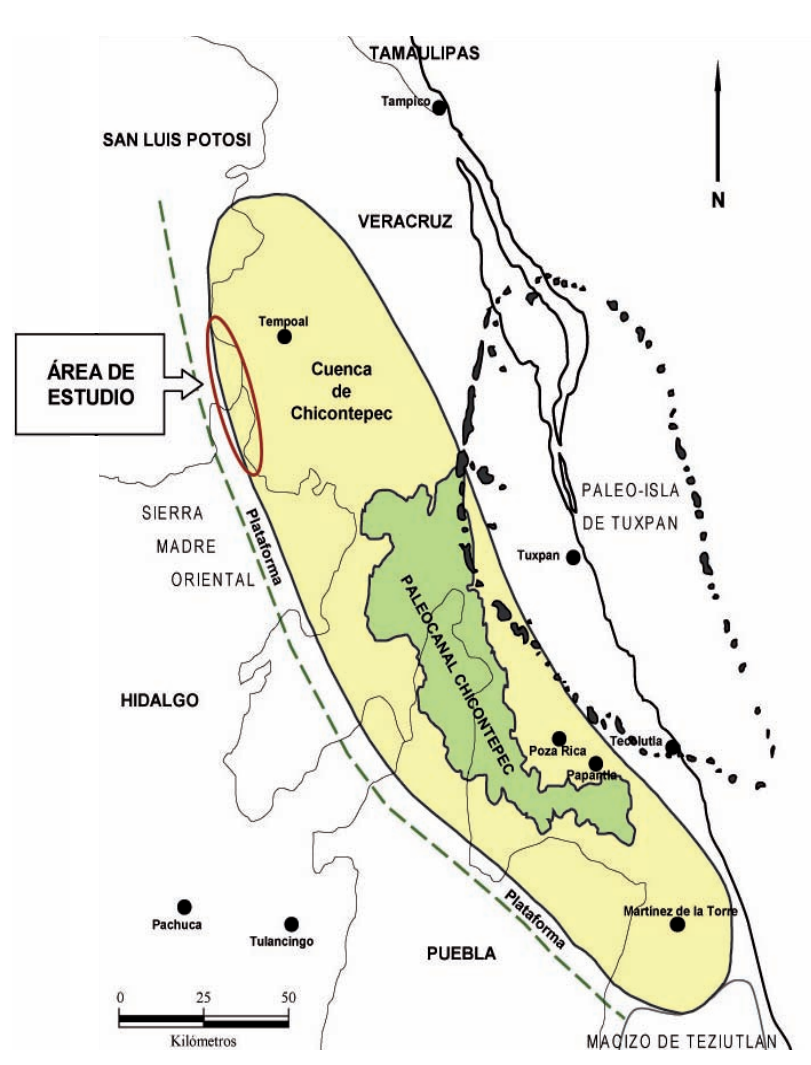

Figura 2. Ubicación del área de estudio dentro de la Cuenca de Chicontepec. Complementada de Schlumberger (1984)

Proponer un modelo paleosedimentario regional conceptualizado, sobre los mecanismos de transporte y distribución de los sistemas turbidíticos.

\section{Métodos de trabajo}

En el presente proyecto de investigación la secuencia estratigráfica paleógena se estudió aplicando los conceptos de interpretación propuestos por Mutti et al. (1972) y Ricci (1975) para tener un mejor entendimiento sobre el origen y evolución de sus facies sedimentarias y de su distribución espacio-temporal, con el propósito de que sirvan a la exploración petrolera como criterios complementarios de apoyo, con otros geológico-geofísicos, facilitando su identificación en el subsuelo profundo de la cuenca terciaria.

Para alcanzar los objetivos mencionados, se identificaron, midieron y caracterizaron en el campo las secuencias sedimentarias en seis afloramientos, donde los criterios básicos para su estudio fueron principalmente litoestratigráficos secuenciales, identificación de estructuras sin-sedimentarias externas e internas y estructuras estratigráficas pene-contemporáneas con deformación intraformacional.
En el laboratorio se estudiaron petrográficamente muestras líticas representativas, colectadas en afloramientos, cuantificando sus características petrográficas, texturales y composicionales por medio de conteos estándar de puntos y con el analizador de imágenes, usando un microscopio petrográfico/mineralógico, marca Nikon, equipado con objetivos 5X, 10X, 20X y 40X, cámara Hitachi CCD modelo KP MIE/K blanco y negro, y el software Enterprise Omnimet distribuido por Buelher que opera bajo ambiente Windows.

\section{Trabajos geológicos previos}

El Léxico Estratigráfico del Servicio Geológico Mexicano (2007), resalta que los primeros estudios bioestratigráficos realizados en la Formación Chicontepec, los refieren al Eoceno (Dumble, 1918; Belt, 1925; Muir, 1936; Nájera, 1952) y también se menciona que trabajos posteriores detallaron y ampliaron su alcance estratigráfico, por ejemplo, Gamper (1977) le asigna una edad de Paleoceno tardío al Eoceno temprano, con base en el registro de asociaciones de foraminíferos; López-Ramos (1979) la sitúa desde Paleoceno (Chicontepec Inferior) al Eoceno (Chicontepec Medio y Chicontepec Superior) y Cantú-Chapa (1985) en Bitter (1993), refiere la Chicontepec a la parte alta del Paleoceno tempranoEoceno temprano.

Busch et al. (1978), se enfocan al estudio estratigráfico y estructural de las turbiditas de Chicontepec, esencialmente en la porción sureste de la cuenca de Tampico-Misantla.

Bitter $(1983,1993)$ en la cuenca de Chicontepec del centro-oriente de México caracteriza petrográfica y mineralógicamente las secuencias estratigráficas de la Formación Chicontepec; además, por medio de la identificación y medición vectorial de las estructuras sedimentarias primarias contenidas en la columna estratigráfica del Paleoceno-Eoceno Inferior; determinó las fuentes de suministro de los sedimentos terrígenos y la dirección y sentido de las paleocorrientes dominantes del fondo marino, que gobernaron el transporte y la distribución de las areniscas paleógenas, genéticamente relacionadas con el surgimiento de la Sierra Madre Oriental y la emersión subaérea del macizo de Teziutlán.

Aguayo y colaboradores (2006) presentan una síntesis de la Geología Regional de la cuenca de Chicontepec del centro-oriente de México, durante el III Simposio: La Investigación y Desarrollo Tecnológico en la Facultad de Ingeniería, UNAM, como antecedente para el estudio del noroccidente de la cuenca de Chicontepec en afloramientos. 
Santillán (2009) caracteriza las facies turbidíticas en afloramientos en el noroeste de la cuenca de Chicontepec, identificando subambientes de abanico medio e inferior en depósitos paleosedimentarios marinos profundos.

La mayor contribución sobre la información superficial y del subsuelo de la cuenca de Chicontepec, se ha generado en PEMEX Exploración-Producción (PEP) y en el Instituto Mexicano del Petróleo (IMP), como informes técnicos inéditos y de difícil acceso público.

\section{Evolución tectono-estratigráfica regional}

La Formación Chicontepec del Paleoceno al Eoceno Inferior, ha sido tradicionalmente descrita como una secuencia "flysch", con más de 2,000 metros de espesor de interestratificaciones delgadas y gruesas de lutitas, areniscas calcáreas y siliciclásticas; texturalmente finas a gruesas, graduando hacia la cima de la secuencia a lutitas limosas (Bitter, 1983 y 1993). La Chicontepec aflora en la porción occidental y sureste del margen de la cuenca Tampico-Misantla; geográficamente se sitúa en la parte norte del estado de Veracruz, en el extremo sur del estado de Tamaulipas y en las porciones más orientales de los estados de San Luis Potosí, Hidalgo y norte de Puebla.

Los sedimentos terrígenos de la Formación Chicontepec, son consecuencia del levantamiento tectónico y la erosión de las rocas de la Sierra Madre Oriental, ocurrido durante el Cretácico tardío hasta el Paleógeno temprano; de la paleo-isla de Tuxpan al oriente y del macizo de Teziutlán al sur; con el consecuente transporte y depósito de los sedimentos resultantes en franca progradación hacia el interior de la cuenca y del paleocanal de Chicontepec, como sistemas turbidíticos marinos y profundos (figura 3).

La columna estratigráfica del Paleoceno Inferior y Medio se erosionó en la mayor parte de la cuenca, durante el Paleoceno tardío-Eoceno temprano y específicamente, a lo largo del margen occidental y sur de la isla de Tuxpan, también fueron erosionadas las rocas basamentales de la cuenca terciaria, del Cretácico y del Jurásico Superior. Este proceso erosivo marino dio origen al Cañón o Paleocanal de Chicontepec que comprende un área de $3,300 \mathrm{~km}^{2}$ cuya longitud es $123 \mathrm{~km}$ con una anchura que varía de 12 a $23 \mathrm{~km}$. La columna estratigráfica paleógena en el paleocañón, comprende alternancias rítmicas de sedimentos arcillosos y arenosos, formando cuerpos lenticulares y tabulares lateralmente discontinuos, constituidos por arena arcillosa y limo areno-arcilloso, intercalados e interdigitados lateral y verticalmente.
El espesor estratigráfico de la Formación Chicontepec en el paleocañón, es variable en su diferentes sitios; en la porción norte, es del orden de $100 \mathrm{~m}$; en su extremo occidental se han llegado a determinar espesores, entre $700 \mathrm{y}$ hasta $2000 \mathrm{~m}$. Por su contenido fosilífero esencialmente bentónico, los sedimentos de la formación Chicontepec sugieren condiciones batimétricas mayores a los 200 metros, en ambientes nerítico externo a batial; sin embargo, con ichnofósiles, Bitter (1993) considera que la cuenca sedimentaria pudo alcanzar profundidades de al menos $500 \mathrm{~m}$, en ambientes batiales.

\section{Modelo de facies turbiditicas}

El modelo aplicado en este trabajo, es el de sistemas turbidíticos antiguos, propuesto por Mutti (1972), que corresponde a una distribución espacial de litofacies que caracterizan a los sub-ambientes de abanico interno, medio y externo, cuyos flujos de densidad fueron transportados dentro de sistemas canalizados y depositados al pie de los taludes de forma abanicada y también, debidos a desprendimientos masivos de sedimentos no canalizados provenientes del talud de la cuenca por deslizamientos, derrumbes y como flujos de escombros; todos ellos también depositados al pie del talud como "aprones"; los sedimentos resultantes estuvieron

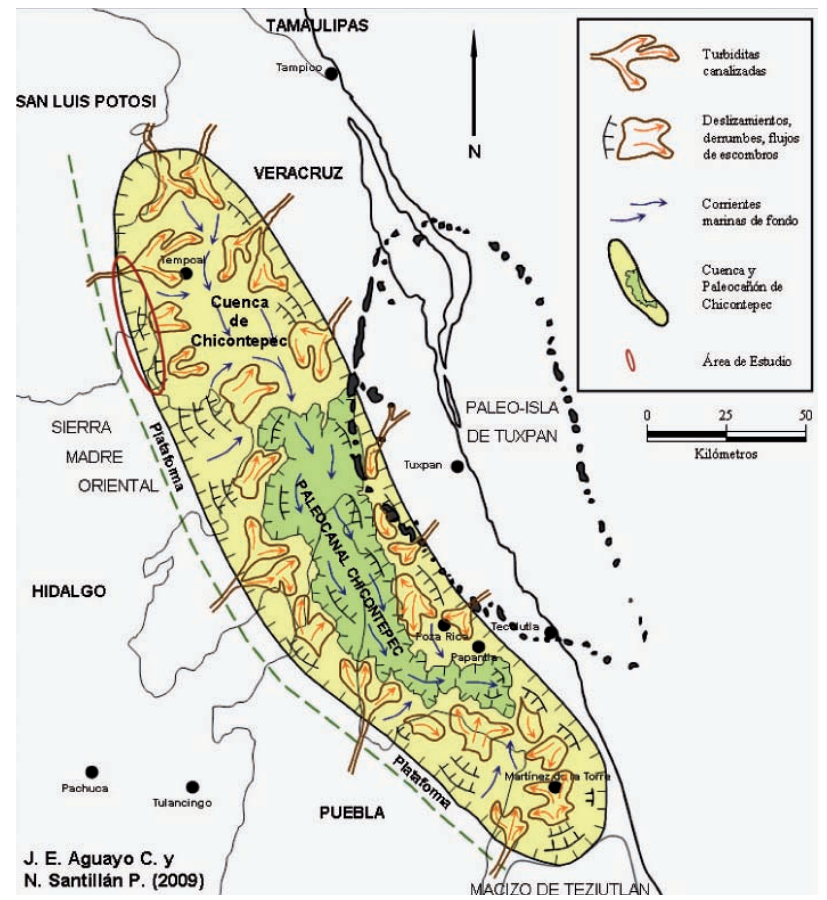

Figura 3. Modelo conceptual de la cuenca de Chicontepec (propuesto en este trabajo), en donde se ilustran los mecanismos esquematizados de transporte y sedimentación. Complementada de Schlumberger (1984) 
sujetos a la acción de las corrientes del piso marino profundo, que generaron sistemas turbidíticos.

La clasificación de litofacies propuesta por Mutti et al. (1972) y Ricci (1975), comprende siete facies descritas alfabéticamente de la A a la $\mathrm{G}$ y las relacionan a los procesos sedimentarios de densidad que ocurren durante la formación del abanico submarino. Con la caracterización y distribución de las litofacies se establecen parámetros sobre la geometría del depósito, estructuras internas de los estratos y de sus variaciones texturales, laterales y verticales; todos ellos y de forma integral, conducen a interpretar sus mecanismos de transporte y depósito.

En la figura 4 se ilustran los principales atributos texturales de las facies A-G en el modelo propuesto por Mutti et al. (1972), empleados para caracterizar e interpretar los afloramientos estudiados en este trabajo.

\section{Resultados y discusión}

Los accesos a los sitios de los afloramientos estudiados, inicialmente son por las carreteras federales número 85 (México-Cd. Valles, SLP) y 105 (Pachuca-MolangoHuautla de Juárez Hgo.); posteriormente por los caminos vecinales que conectan a los poblados de Cuatatlán-SanFelipeOrizatlán,Hgo.-Tamazunchale-Alfredo M. Terrazas SLP y otros circunvecinos. Los sitios de los afloramientos visitados dentro de la Cuenca de Chicontepec se muestran en la figura 5.

\section{Ubicación de los afloramientos en el modelo con- ceptual}

En la figura 6, en (A) se ilustra en planta el modelo de abanico submarino propuesto por Mutti et al. (1972) y la posición relativa del abanico interno, medio y externo de la planicie de la cuenca, así como las litofacies asociadas a ellos. En (B) se esquematiza una columna regresiva hipotética. Los números indican la ubicación de los sitios estudiados de las secuencias estratigráficas en los afloramientos aislados, caracterizadas e interpretadas en este trabajo como facies turbidíticas de abanico medio y externo de la formación Chicontepec inferior; edad determinada por la posición regional de la unidad estratigráfica dentro de la cuenca.

\section{Sitio 1: Afloramiento "Puente Axtla de Terrazas"}

Puente Axtla de Terrazas, SLP. De Tamazunchale, SLP $35 \mathrm{~km}$ al norte, por la carretera federal 85 (Ciudad de México-Ciudad Valles) y del entronque $3 \mathrm{~km}$ hacia el oriente y $350 \mathrm{~m}$ antes del poblado Alfredo M. Terrazas. Coordenadas: 14Q (512,495 m E, 2'369,921 m N).

$\mathrm{El}$ afloramiento tiene un espesor de $46.25 \mathrm{~m}$ con un rumbo general de la secuencia $\mathrm{NW} 36^{\circ} \mathrm{SE}, 61^{\circ} \mathrm{SW}$.

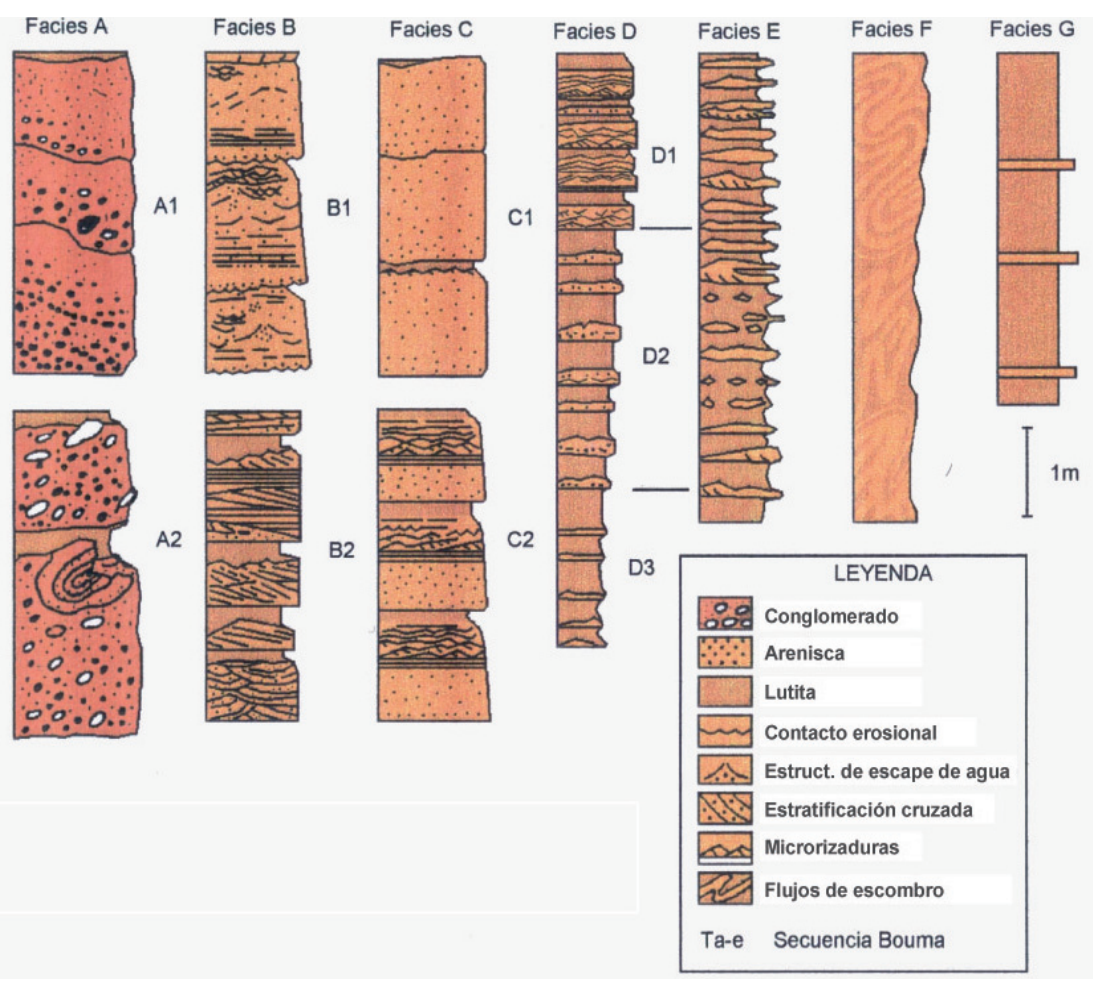

Figura 4. Clasificación de facies turbidíticas propuesta por Mutti et al. (1972) 


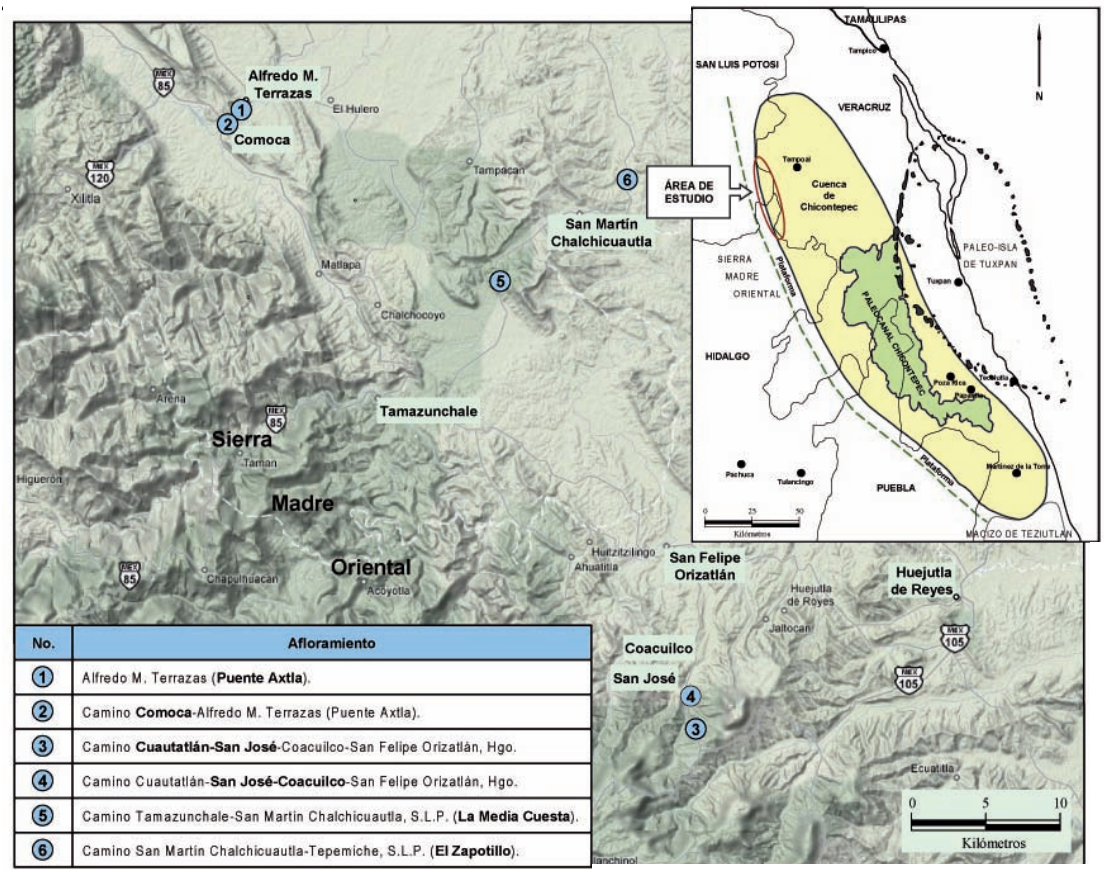

Figura 5. Localización de los afloramientos visitados dentro de la Cuenca de Chicontepec (Modificada y complementada de Google-Imágenes (2009) y Schlumberger (1984)
(A)

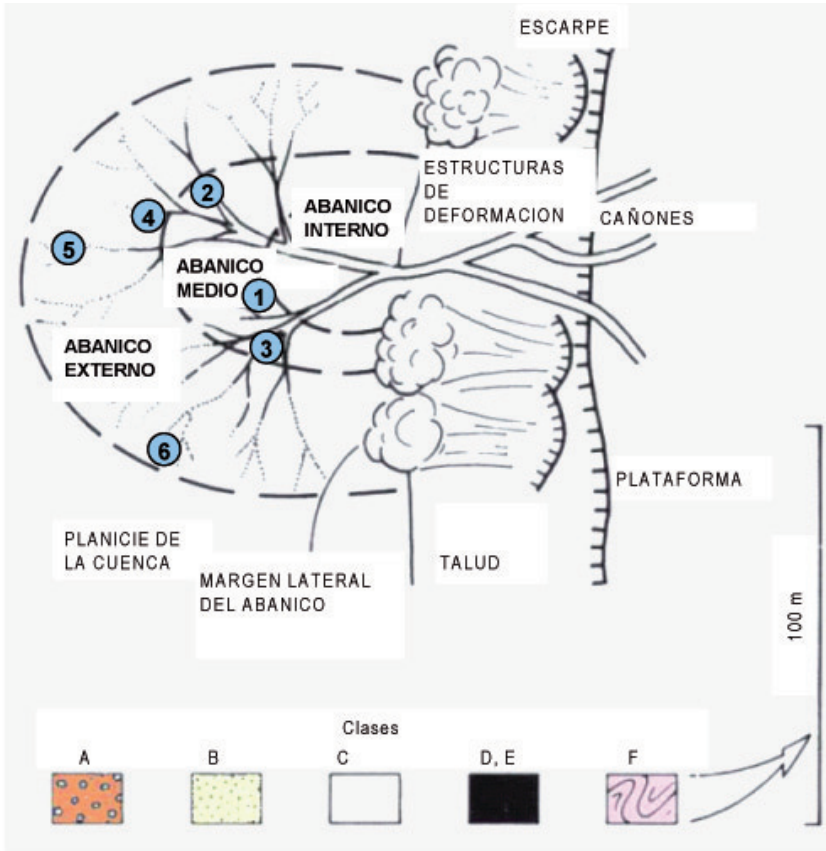

(B)

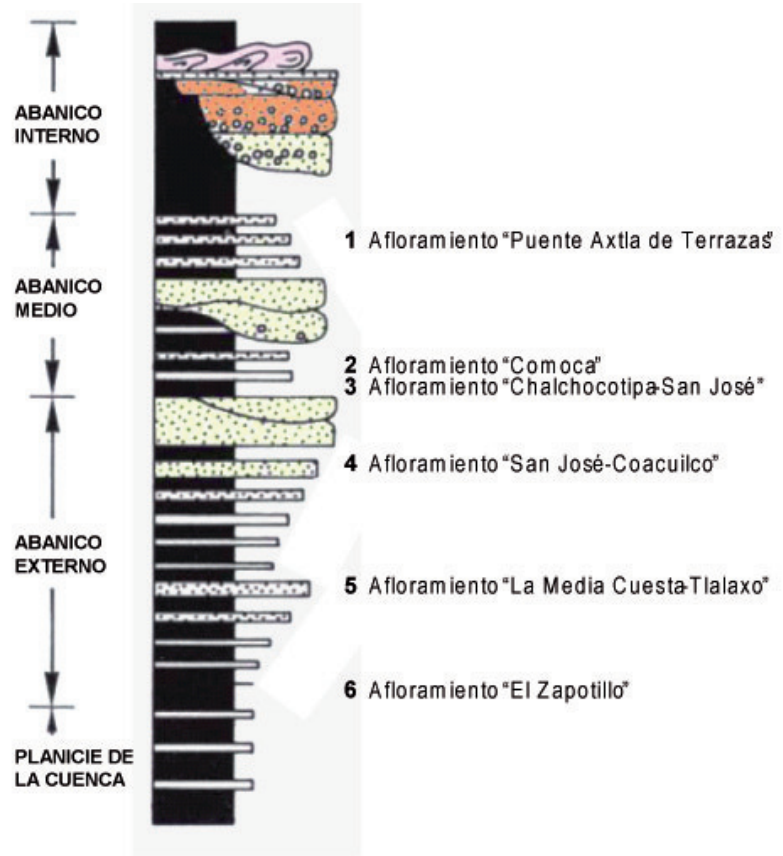

Figura 6. (A) Vista en planta del modelo de abanico submarino conceptualizado; (B) Secuencia regresiva hipotética de un modelo de abanico submarino (adaptado después de Mutti et al., 1972). Los números representan los sitios estudiados e interpretados en este trabajo dentro de los subsistemas de abanico 


\section{Miembro PAT1}

Este afloramiento es la base de la columna estratigráfica medida con un espesor de $6.85 \mathrm{~m}$ que está invertida en dirección hacia el NE $40^{\circ}$ con una inclinación de $50^{\circ}$ (Foto 1.1). Litológicamente está formada por intercalaciones de capas gruesas y medianas de areniscas de grano fino, color gris claro y ocre por intemperismo; los estratos varían en espesor entre $0.85 \mathrm{~m}$ a $1.0 \mathrm{~m}$ y están interestratificados con capas delgadas de areniscas limosas y limos arcillosos de entre 10 y $12 \mathrm{~cm}$ de espesor. Todas las capas presentan adelgazamientos laterales y las láminas texturalmente más finas están altamente

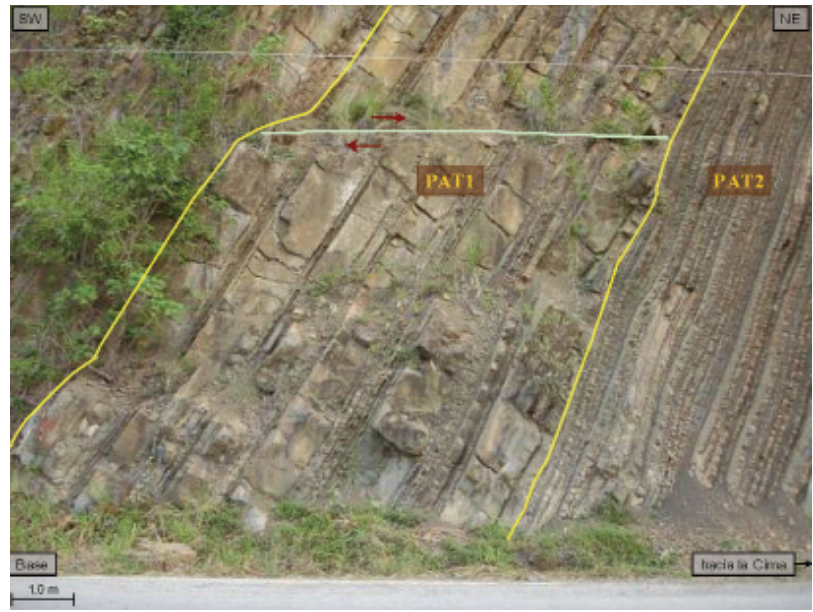

Foto 1.1. Sección estratigráfica invertida hacia el NE; obsérvese las megarrizaduras de fondo en la parte superior de los estratos y ondulaciones por carga diferencial en sus bases. Este miembro subyace al PAT2

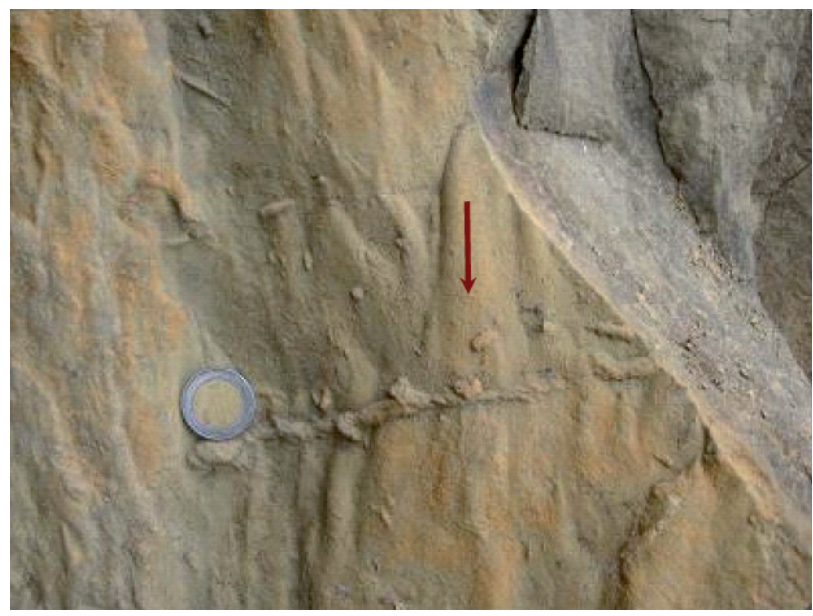

Foto 1.2. Superficie de estratificación bioturbada con ichnofósiles Megagrapton irregulare (?) y estructuras de flujo "flute casts", hacia la cima del estrato. La flecha indica el sentido general del flujo hacia el SE. Moneda como escala: $2.1 \mathrm{~cm}$ bioturbadas observándose ichnofósiles del género $\mathrm{Me}$ gagrapton irregulare (?) (foto 1.2) y Fucusopsis angulata (foto 1.3).

La columna presenta estructuras sedimentarias primarias, debidas a corrientes de fondo, tales como "flute casts" y megarrizaduras, así como estructuras de arrastre de partículas: "groove", "prood" y "bonce casts" (Foto 1.3); todas ellas orientadas hacia el SE $35^{\circ}$, transversales a la dirección del transporte másico sedimentario que tiene una dirección preferencial hacia el NE $40^{\circ}$.

El miembro PAT1 se interpreta como depósito sedimentario no canalizado y con megarrizaduras por corrientes de fondo en la superficie lobular.

\section{Miembro PAT2}

Sobreyace estratigráficamente al miembro anterior PAT1, caracterizado por una alternancia de areniscas de grano fino y lutitas limosas, con espesor total de $3.50 \mathrm{~m}$ (foto 1.1); los espesores de los estratos individuales varían entre 2 y $12 \mathrm{~cm}$; algunos de los mismos corresponden a pequeñas zonas de canalización observándose estructuras de corte y relleno, cuyos espesores son entre 5 y $8 \mathrm{~cm}$ (foto 1.4).

Sobre la base de los estratos de arenisca se observan estructuras por actividad orgánica, las cuales pudieran corresponder a Megagrapton irregulare (?).

Esta parte de la secuencia podría corresponder de acuerdo con Mutti et al. (1989) a una zona de "overbank", quienes definen los depósitos de desbordamiento en sistemas turbidíticos antiguos como sedimentos de grano fino (areniscas de grano fino y limonitas-lutitas) con estratificación delgada, confinadas entre zonas de canalización.

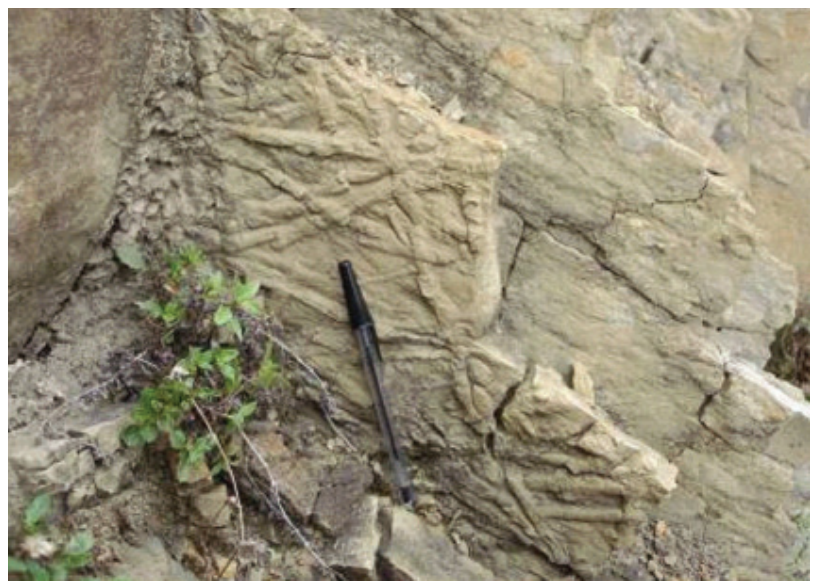

Foto 1.3. Abundante bioturbación sobre la superficie del estrato; nótese los ichnofósiles Fucusopsis angulata. Pluma como escala: $14.9 \mathrm{~cm}$ 


\section{Miembro PAT3}

Sobreyace estratigráficamente a los miembros anteriores, ya que la secuencia tiene un espesor medido 15.38 $\mathrm{m}$ y en su parte basal se observa un estrato grueso de $2.10 \mathrm{~m}$ constituido de arenisca media a gruesa a la que le sobreyace interestratificaciones de capas medianas a gruesas variando entre 0.5 a $1.5 \mathrm{~m}$ compuestas por areniscas cuarzo-feldespáticas con textura media a gruesa y matriz calcárea (foto 1.5). Entre estas capas se observa la presencia de horizontes delgados a laminares de arcillas impregnadas con hidrocarburo cristalizado (gilsonita) (foto 1.6). También se observan estructuras de corriente de "flute casts" de unos $15 \mathrm{~cm}$ de longitud, lo que sugiere que la corriente de fondo era de magnitud alta, así como "crescent casts" y "groove casts", los cuales, al igual que las marcas de corriente antes mencionadas, presentan una dirección de $\mathrm{S} 35^{\circ} \mathrm{E}, 59^{\circ} \mathrm{SW}$ (foto 1.7). Esta unidad estratigráfica se interpreta como depósito transicional entre lóbulo y canal interlobular.

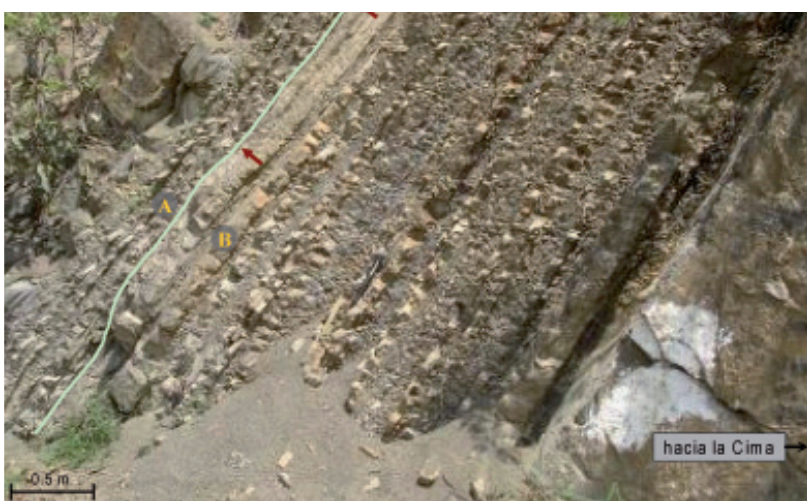

Foto 1.4. Sección invertida con alternancia de areniscas y lutitas; obsérvense estratos cóncavos canalizados (señalados por las flechas) (A: base, B: cima)

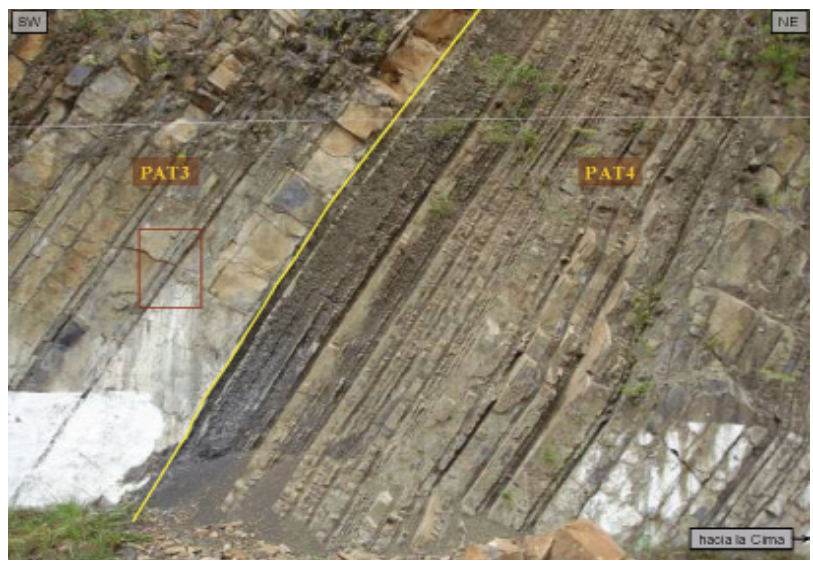

Foto 1.5. Sección estratigráfica invertida, en donde se observan la parte superior del miembro PAT3 y la inferior-media del miembro PAT4

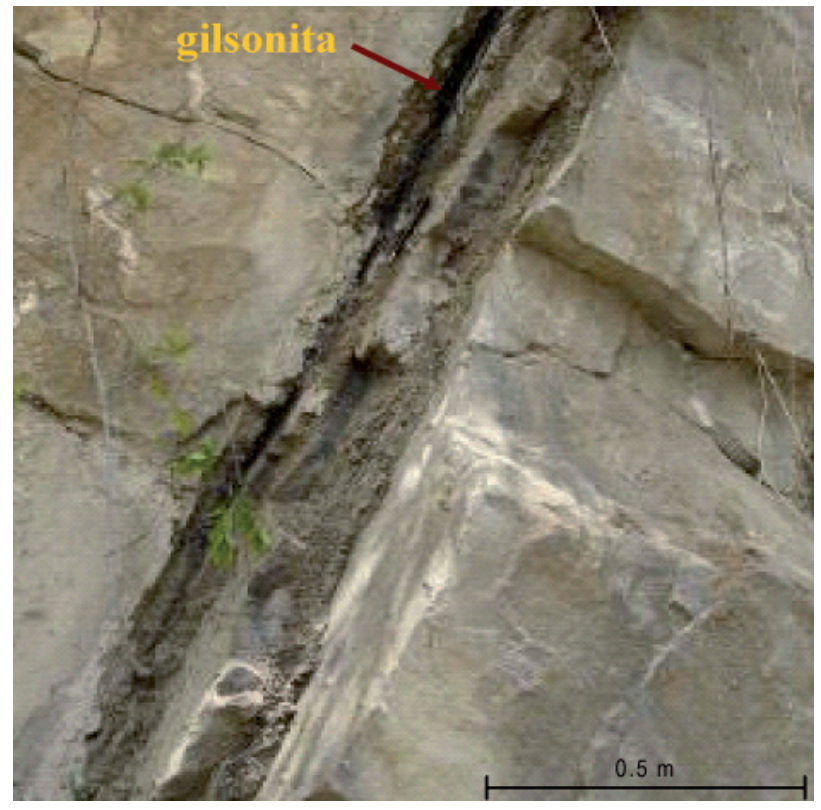

Foto 1.6. Acercamiento de la figura anterior (señalado por el rectángulo), nótese el hidrocarburo cristalizado (gilsonita) emplazado entre planos de estratificación (señalado por la flecha)

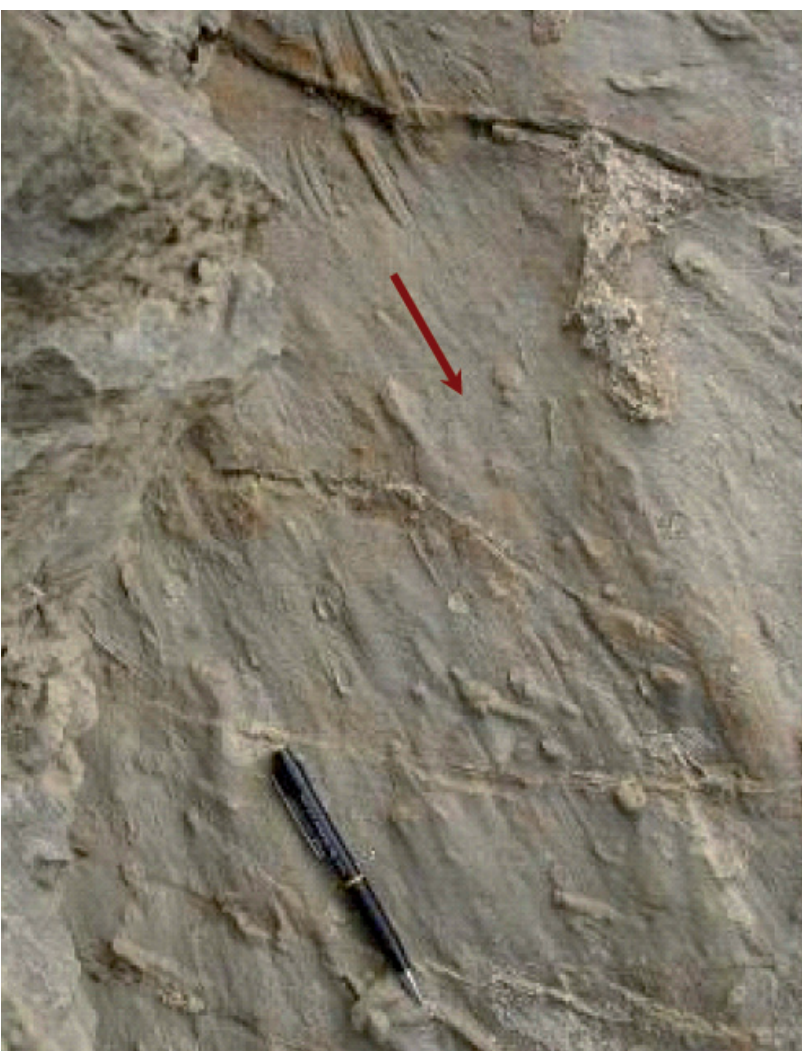

Foto 1.7. Marcas de corriente: "flute casts", "crescent casts" y "groove casts"; la flecha indica el sentido de flujo, hacia el SE. Pluma como escala: $13.8 \mathrm{~cm}$ 


\section{Miembro PAT4}

Sobreyace a los anteriores con un espesor de $11.42 \mathrm{~m}$, en cuya base se encuentra una alternancia de $1.15 \mathrm{~m}$ de espesor, conformada por areniscas de grano fino con espesores de $8 \mathrm{~cm}$ de carácter homogéneo y lutitas-limolitas con espesores que varían desde los 15 hasta los $25 \mathrm{~cm}$; de la base de la secuencia hasta su parte media es estratocreciente, formada por intercalaciones de arenisca con textura media y fina y con espesores hasta de 75 $\mathrm{cm}$ (foto 1.5). La parte superior de este miembro es estrato decreciente formado por horizontes delgados de areniscas intercaladas con lutitas y limonitas impregnadas con gilsonita en las microfracturas.

Los estratos gruesos de las areniscas son cóncavos hacia el oriente, debidas a rizaduras de fondo (foto 1.8), en la base de los estratos de areniscas existe abundancia de huellas de ichnofósiles, los cuales son identificados como Fucusopsis angulata (repichnia), organismo característico de facies abisales; así como de "flute casts", los cuales nos permiten inferir la polaridad y el sentido de corriente hacia el $\mathrm{S} 40^{\circ} \mathrm{E}$.

Las características sedimentarias de esta unidad, sugieren que su depósito se originó en una zona de "overbank" o de desbordamiento.

\section{Miembro PAT5}

Es la parte superior de la secuencia estratigráfica medida, tiene un espesor de $9.50 \mathrm{~m}$ y está caracterizado por alternancias de areniscas con estratificación gruesa que varían entre $2 \mathrm{~cm}$ hasta $1.9 \mathrm{~m}$; estos estratos están intercalados con cuerpos delgados de arenisca de grano medio de 5 y $6 \mathrm{~cm}$ de espesor y lutitas de 1 a $2 \mathrm{~cm}$ (foto 1.9).

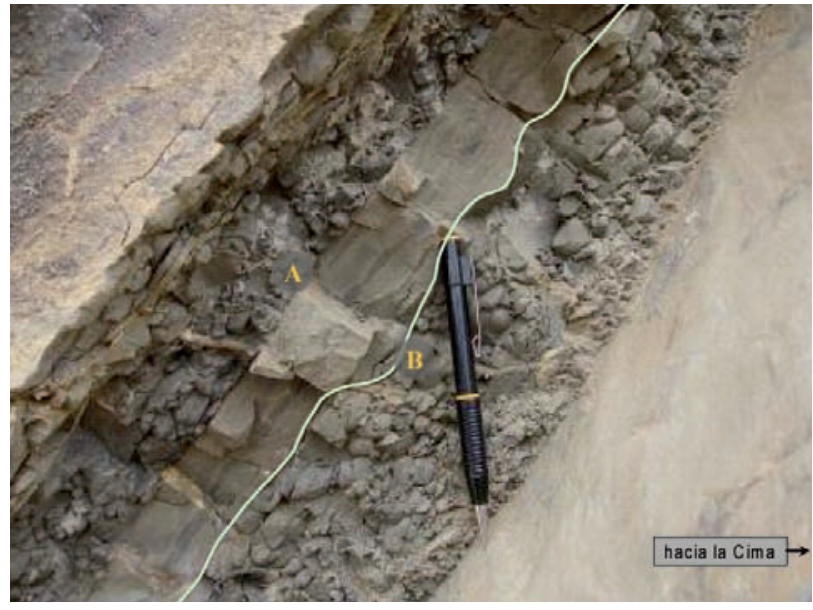

Foto 1.8. Lentes limo-arenosos intercalados con estratos de arenisca; obsérvense rizaduras por corrientes de fondo (A: base, B: cima); pluma como escala: $13.8 \mathrm{~cm}$
El estrato más potente de $1.9 \mathrm{~m}$ de espesor contiene areniscas de textura media y presenta una forma convexa en su superficie superior y plana en la base del mismo, haciéndose más delgado lateralmente. Estructura que es interpretada como megarrizaduras por corrientes de fondo; la base del estrato presenta poca bioturbación, así como pocas marcas de corriente ("flute casts"), las cuales presentan una dirección de flujo hacia el S $40^{\circ} \mathrm{E}$ ).

En la parte superior de la secuencia, las areniscas tienen hasta $40 \mathrm{~cm}$ de espesor, dentro de las cuales se observan pequeñas laminaciones paralelas de 2 a 5 $\mathrm{mm}$, presentando estos horizontes finos entre 8 y $10 \mathrm{~cm}$ de espesor; también se tiene la presencia de una estructura en forma cuspada, debido al escape de fluidos (foto 1.9).

De manera general, la secuencia presenta en sus diversas unidades una alternancia de eventos correspondientes a zonas de transición lóbulo-canal y lóbulos (facies B, C y D, Mutti et al., 1972), caracterizadas por la presencia de gradación normal, laminaciones y rizaduras, así como una gran cantidad de marcas de corriente con orientación hacia el $\mathrm{S} 35^{\circ} \mathrm{E}$, lo cual permite inferir que los sedimentos fueron transportados como flujos de grano y corrientes turbidíticas de velocidad baja a media.

Los lóbulos presentan espesores muy variables, desde los $25 \mathrm{~cm}$ hasta el orden de los $9 \mathrm{~m}$, los cuales pueden corresponder a facies intermedias de canal en la parte del abanico medio del sistema turbidítico subma-

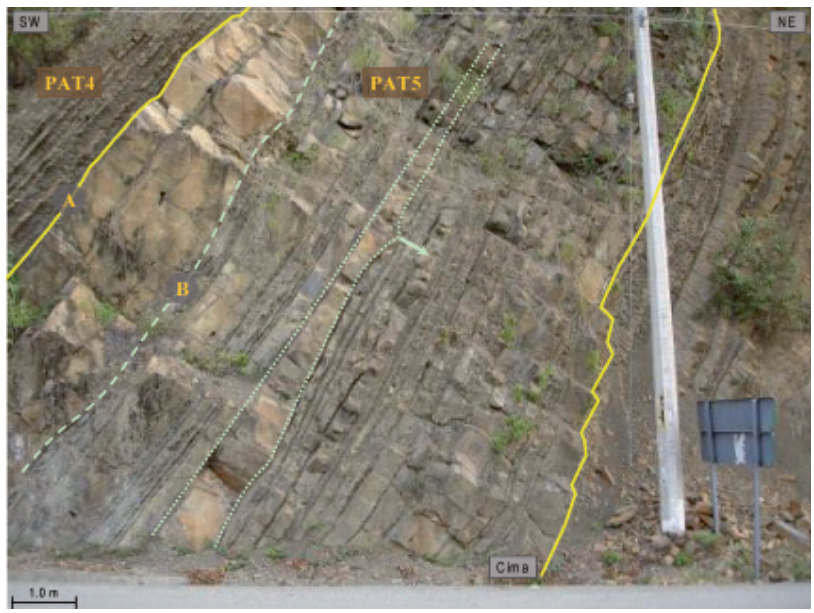

Foto 1.9. Sección estratigráfica invertida, obsérvense los miembros PAT4 y PAT5 en la cima de la sección estratigráfica medida. Nótese las megarizaduras de fondo con la parte inferior recta o ligeramente ondulada por compactación diferencial (A: base); la parte superior es convexa (B: cima). Obsérvese también la estructura en forma cuspada por escape de fluidos (señalada por la flecha) 
rino, posiblemente por el desarrollo parcial del desbordamiento ó extensión lateral de una corriente turbidítica confinada.

\section{Sitio 2. Afloramiento "COMOCA"}

Comoca, SLP, en las inmediaciones del entronque de la carretera Federal 85, $300 \mathrm{~m}$ hacia el oriente en el camino vecinal hacia el poblado Alfredo M. Terrazas. Coordenadas: 14Q (511,892 m E, 2’368,837 m N).

$\mathrm{El}$ afloramiento tiene un espesor medido de $9.45 \mathrm{~m} \mathrm{y}$ es estratodecreciente. Rumbo general de la secuencia: $\mathrm{N}$ $47^{\circ} \mathrm{W}, 01^{\circ} \mathrm{NE}$ (foto 2.1 ).

\section{Miembro COM1}

Secuencia medida con $3.04 \mathrm{~m}$ de espesor, conformada en la base por un paquete de $1.85 \mathrm{~m}$, compuesto por estratos de areniscas de grano medio a fino, que varían desde los $3 \mathrm{~cm}$ hasta los 12 y $15 \mathrm{~cm}$, intercalados con horizontes delgados de limolitas-lutitas de igual espesor.

En la cima se encuentra una alternancia muy homogénea de areniscas de grano fino a medio y limolitaslutitas con $1.19 \mathrm{~m}$ de espesor; presenta una estratificación rítmica; los espesores de los horizontes individuales texturalmente más finos tienen un espesor de 2 a $6 \mathrm{~cm}$ y están intercalados entre capas finas y laminares de areniscas texturalmente finas.

\section{Miembro COM2}

Esta unidad tiene un espesor aproximado de $6.41 \mathrm{~m}$, el intervalo inferior tiene un espesor de $3.17 \mathrm{~m}$ y está formado por intercalaciónes rítmicas de areniscas de grano fino a medio y limolitas-lutitas, cuyos espesores varían de entre 10 a $15 \mathrm{~cm}$ hasta $35 \mathrm{~cm}$ e incluso alcanzan $40 \mathrm{~cm}$ de espesor, que están intercaladas con estratos limo-arcillosos.

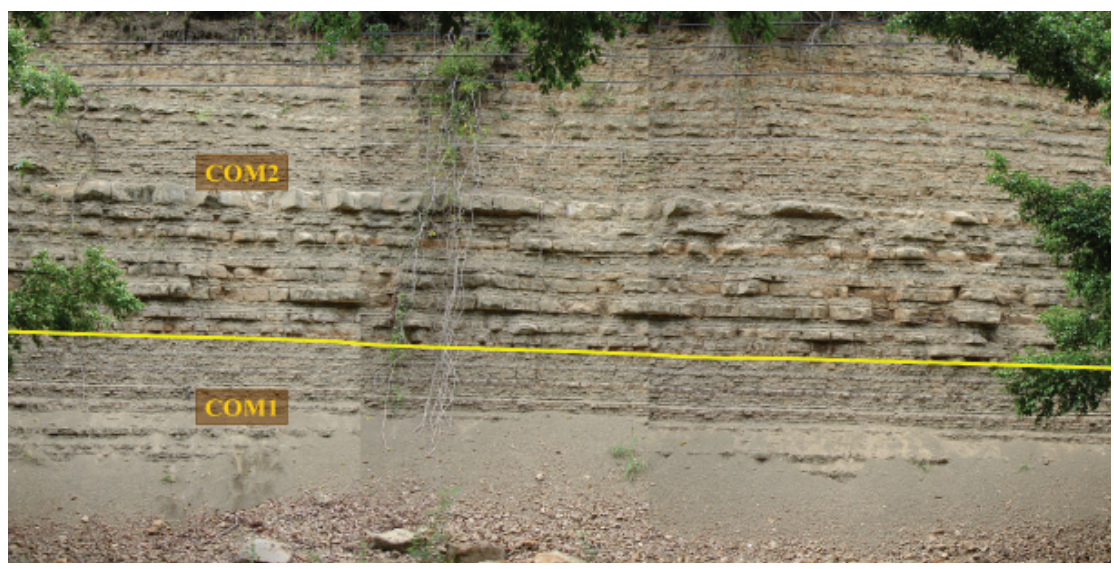

La columna sobreyaciente tiene un espesor medido de $3.24 \mathrm{~m}$ y compuesta por intercalaciones de areniscas y limolitas-lutitas; las areniscas varían de 2 a $5 \mathrm{~cm}$ y localmente hasta $10 \mathrm{~cm}$; los cuales están intercalados con horizontes texturalmente más finos con espesores promedio de 5 a $8 \mathrm{~cm}$.

Los miembros COM1 y COM2 son depósitos estratigráficos cíclicos sobrepuestos, presentando ambos una asociación estratodecreciente. Por otro lado, el COM2 presenta evidencias de bioturbación con diversos grados de intensidad, lo cual no se observa en el miembro infrayacente COM1.

Esta secuencia estratigráfica se interpreta de ambiente de abanico medio como lóbulo de desbordamiento, con zonas o intervalos discretos de canalización, cuyas litofacies pueden corresponder a las facies C y D de Mutti et al. (1972).

\section{Sitio 3. Afloramiento "Chalchocotipa/San José"}

Cuautatlán-San José, Hgo., de la carretera federal 105 (Pachuca - Huejutla de Reyes, Hgo.) sobre el camino vecinal Cuautatlán-San Felipe Orizatlán, $4 \mathrm{~km}$ antes de llegar al poblado de San José. Coordenadas: 14Q $(542,820 \mathrm{~m} \mathrm{E}, 2$ '329,011 m N).

El afloramiento tiene un espesor de $11.91 \mathrm{~m}$ con rumbo general de la secuencia que varía entre SE $76^{\circ}$ $\mathrm{NW}, 12^{\circ} \mathrm{SW}$ y SE $72^{\circ} \mathrm{NW}, 20^{\circ} \mathrm{SW}$ (foto 3.1).

\section{Miembro CHSJ1}

Con un espesor medido de $4.06 \mathrm{~m}$, en cuya base se encuentran estratos de areniscas de grano medio a fino, en espesores que varían entre 3 y $15 \mathrm{~cm}$, intercalados con limonitas y lutitas de 2 a $3 \mathrm{~cm}$ de espesor. Se observan zonas de derrumbes y deslizamientos intraformacionales (pliegues convolutos: "décollement") hacia el $\mathrm{NE}$ con espesor de $40 \mathrm{~cm}$ (foto 3.1). Los estratos encajonantes presentan acuñamientos $\mathrm{y}$ truncamientos.

Foto 2.1. Afloramiento de Comoca, en donde se observa la parte superior del miembro COM1 y la secuencia estratodecreciente del miembro COM2 


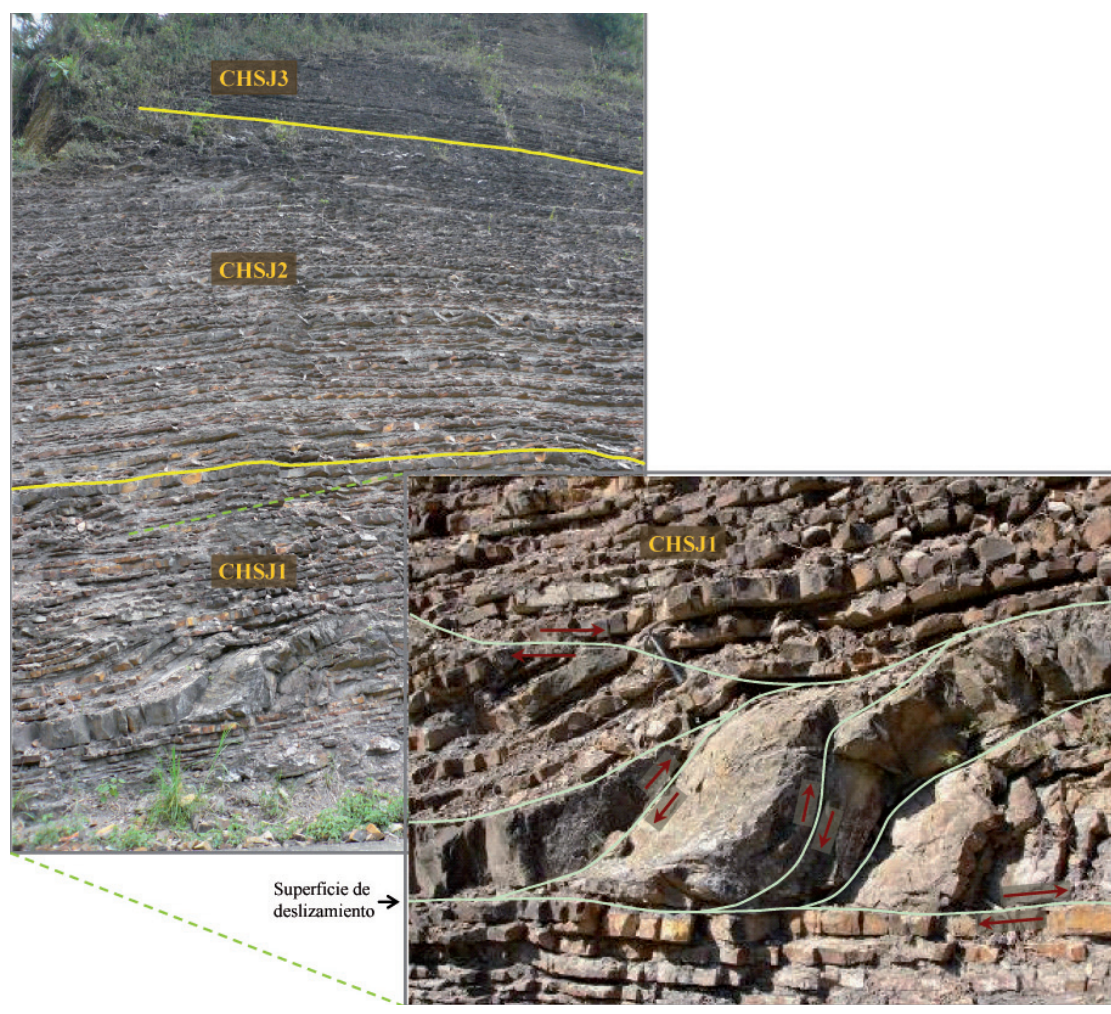

Foto 3.1. Afloramiento en ChalchocotipaSan José, en donde se observan los miembros CHSJ1 a CHSJ3; nótese en la parte basal el truncamiento de los estratos debido al derrumbe y deslizamientos intraformacionales hacia el NE (pliegue convoluto: "décollement"). Las flechas indican la dirección de movimiento relativo (martillo como escala: $31.8 \mathrm{~cm}$.)
Los espesores de los estratos de arenisca de grano medio a fino varían en espesor de 1 a $5 \mathrm{~cm}$ hasta entre 12 y $15 \mathrm{~cm}$, los cuales alternan con estratos de limolitaslutitas en espesores de 4 a $5 \mathrm{~cm}$, hasta $10 \mathrm{~cm}$. Los estratos de areniscas que encajonan a los de la zona del pliegue convoluto ("décollement"), presentan evidencias de bioturbación con la presencia de gran variedad de ichnofósiles (Fucusopsis angulata (?)).

\section{Miembro CHSJ2}

Con un espesor medido de $4.95 \mathrm{~m}$ y con características estratigráficas decrecientes similares al miembro anterior, pero con deformaciones y acuñamientos intraformacionales discretos. Esta secuencia presenta sedimentación rítmica con alternancia de areniscas de grano fino y limolitas-lutitas; los espesores de los estratos de arenisca varían de 2 a $5 \mathrm{~cm}$ y están intercalados con espesores similares de limonitas y lutitas. Se observan marcas de corrientes orientadas hacia el W-E, tales como "flute casts", "crecent casts" y "groove casts"; que se observan en la base de los estratos de las areniscas. Además existe la presencia de ichnofósiles identificados como Fucusopsis angulata (?) (repichnia) de ambientes marinos profundos mayores a los $500 \mathrm{~m}$ (Bitter, 1983).
Miembro CHSJ3

Con un espesor medido de $2.90 \mathrm{~m}$, cuya base consiste de estratos delgados de areniscas/limolitas-lutitas entre 2 a $5 \mathrm{~cm}$ de espesor. La estratificación se hace más delgada hacia la parte superior de la secuencia estratigráfica; en algunos fragmentos sueltos de roca encontrados al pie del afloramiento se logró identificar la presencia de Paleodictyon, organismo característico de facies turbidíticas de zona abisal (ichnofacies Nereites).

El ambiente sedimentario de la secuencia estratigráfica del sitio 3 corresponde a un deposito en la zona intermedia de lóbulos (facies C y E, según Mutti et al., 1972), asociados a zonas de desbordamiento entre canales semiconfinados, cuyos sedimentos fueron transportados como flujos de granos y corrientes de turbidez.

\section{Sitio 4: Afloramiento "San José/Coacuilco"}

San José-Coacuilco, Hgo., del poblado San José (sitio 3), $500 \mathrm{~m}$ antes de Coacuilco, rumbo a San Felipe Orizatlán. Coordenadas: 14Q (542,075 m E, 2’330,593 m N). (foto 4.1).

Secuencia estratigráfica compuesta por areniscas interestratificadas de color gris oscuro, de grano medio, 
en estratos que varían desde 2 hasta $60 \mathrm{~cm}$, los cuales están intercalados con horizontes de limonitas y lutitas que varían entre 2 a $20 \mathrm{~cm}$. Por intemperismo los estratos lodo-arcillosos presentan aspecto nodular y las areniscas sistemas rectangulares. En esta unidad se

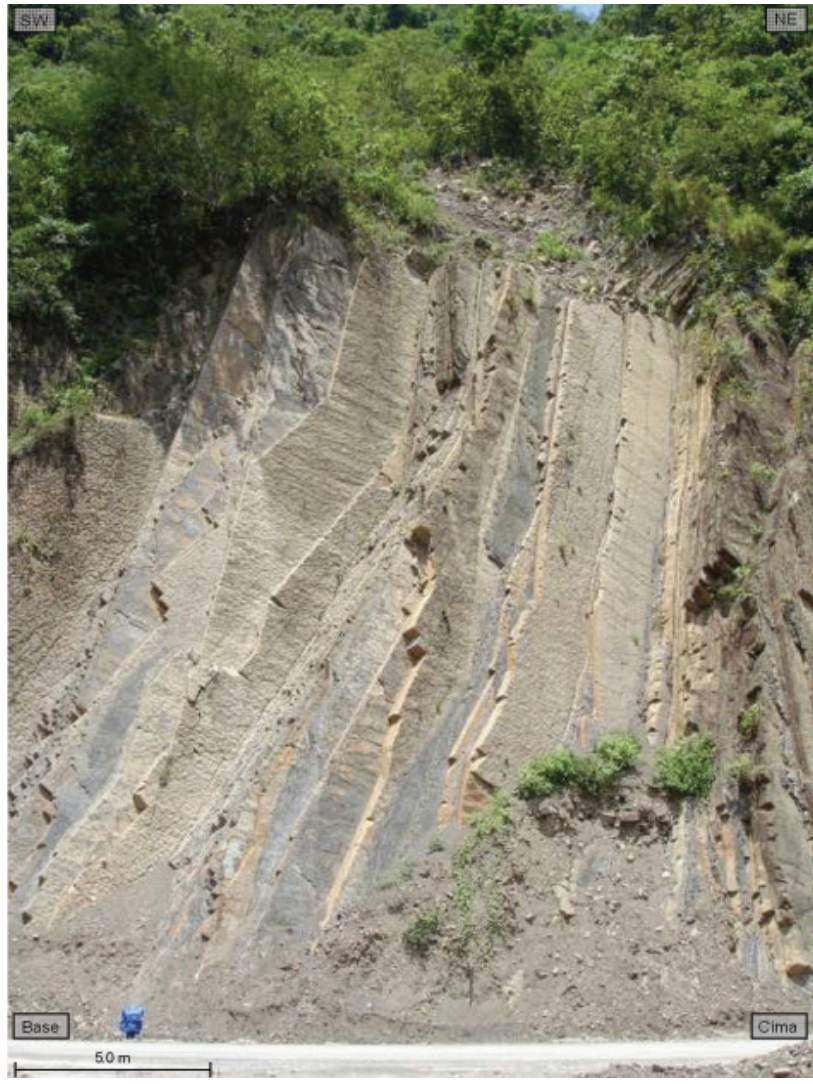

Foto 4.1. Afloramiento de San José-Coacuilco; rumbo general de la secuencia: $\mathrm{N} 35^{\circ} \mathrm{W}, 64^{\circ} \mathrm{NE}$.

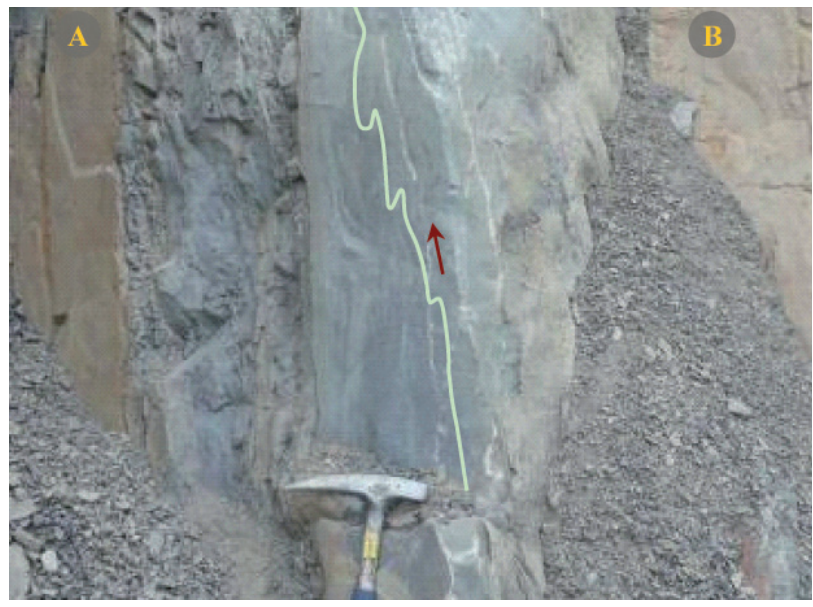

Foto 4.2. Estructuras flamiformes, formadas por corrientes de fondo; dirección del flujo hacia el SE (señalado por la flecha) (A: base, B: cima) (martillo como escala: de $31.8 \mathrm{~cm}$ ) encuentran estructuras sedimentarias primarias formadas por corrientes de fondo: flamiformes (foto 4.2), "flute casts", "prod y bounce casts", así como marcas de ichnofósiles (no identificadas en este trabajo).

Otras estructuras presentes sobre la superficie de estratificación, son las de carga, que observadas de canto o perfil muestran un asentamiento diferencial de las areniscas sobre las arcillas (foto 4.3) y se manifiestan en las areniscas como superficies alabeadas y onduladas (foto 4.4).

Hacia la cima de la secuencia estratigráfica se presenta un plegamiento-fallamiento normal con vergencia al NE, el cual afecta a toda la secuencia en ese sector y regionalmente se puede observar una intensa deformación, desde pliegues recumbentes, hasta pliegues muy cerrados, en donde la posición de la secuencia varia en tan solo unas decenas de metros, pasando de una secuencia horizontal a otras casi verticales; lo que se interpreta como deformaciones intraformacionales, debidas a deslizamientos y derrumbes. Esta interpretación no fue confirmada porque los estratos encajonantes (infra y sobreyacentes) están cubiertos.

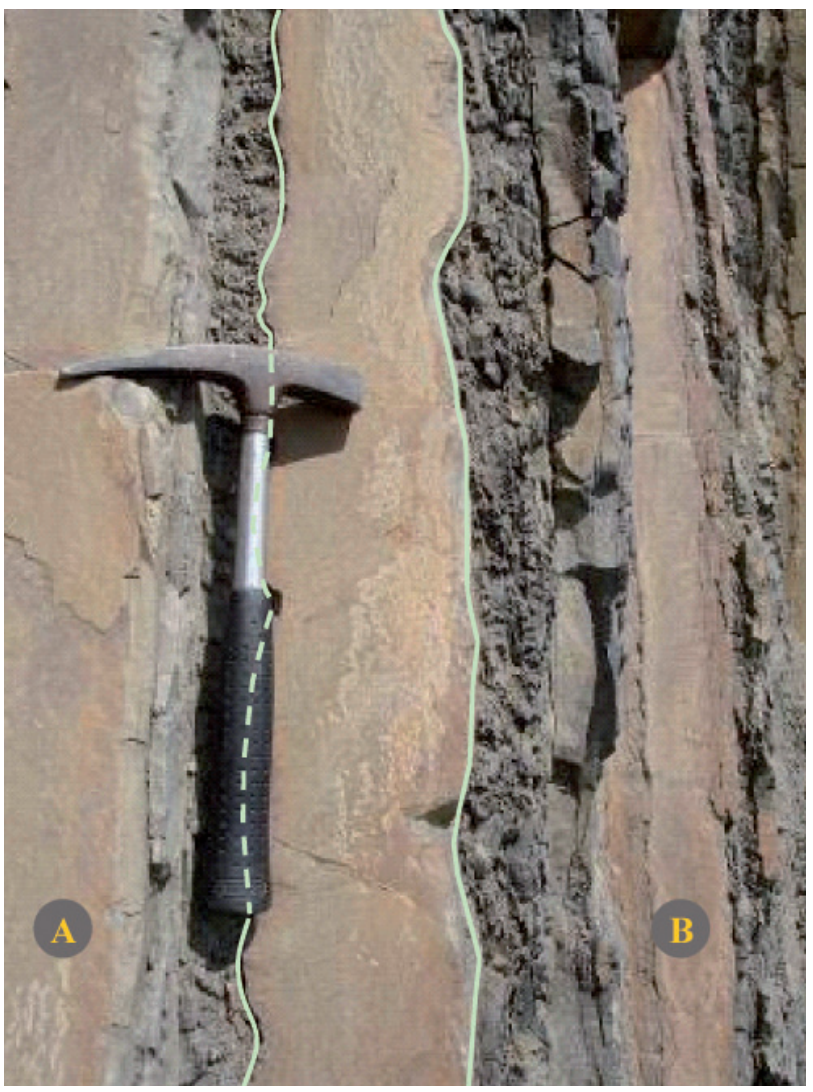

Foto 4.3. Estructura de carga de las areniscas sobre las arcillas por asentamientos diferenciales (vista de perfil) (A: base, B: cima) (martillo como escala: $31.8 \mathrm{~cm}$ ) 
Los regímenes de sedimentación fueron muy variados, los cuales comprenden desde zonas de "overbank" amplias y de relieve suave, hasta zonas de desbordamiento en lóbulo distal; por lo que se infiere que esta secuencia puede corresponder a una facie $C$, según Mutti et al. (1972), bajo condiciones hidrodinámicas de un flujo turbidítico de baja densidad, que pasó de condiciones canalizadas a condiciones de margen de canal.

\section{Sitio 5: Afloramiento "Media Cuesta/Tlalaxo"}

Paraje "La Media Cuesta", SLP, sobre el camino vecinal $20 \mathrm{~km}$ al noroeste de Tamazunchale rumbo a San Martín Chalchicuautla, SLP. Coordenadas: 14Q (529,452 m E, 2'357,970 m N).

El espesor medido es de $7.50 \mathrm{~m}$ y el rumbo general de la secuencia estratigráfica varía entre $\mathrm{N} 63^{\circ} \mathrm{W}, 21^{\circ}$ $\mathrm{NE}$ y $\mathrm{N} 10^{\circ} \mathrm{W}, 20^{\circ} \mathrm{NE}$ (foto 5.1).

\section{Miembro MC1}

Espesor medido de $3.9 \mathrm{~m}$ de la secuencia rítmica compuesta de areniscas de grano fino en estratos delgados de 5 a $6 \mathrm{~cm}$ de espesor, que en su parte superior se intercalan con horizontes de limolitas-lutitas de entre 8 y $15 \mathrm{~cm}$ de espesor; las trazas de bioturbación son escasas y principalmente se observan en la base de los horizontes de las areniscas (foto 5.1)

\section{Miembro MC2}

Espesor medido de $3.61 \mathrm{~m}$ de alternancias rítmicas entre estratos paralelos de areniscas de grano fino a medio, algunos de ellos con clastos calcáreos y lutitas-limolitas, cuyos espesores varían de 1 a $2 \mathrm{~cm}$ (foto 5.2), siendo la interestratificación arenosa más delgada que la del miembro inferior.
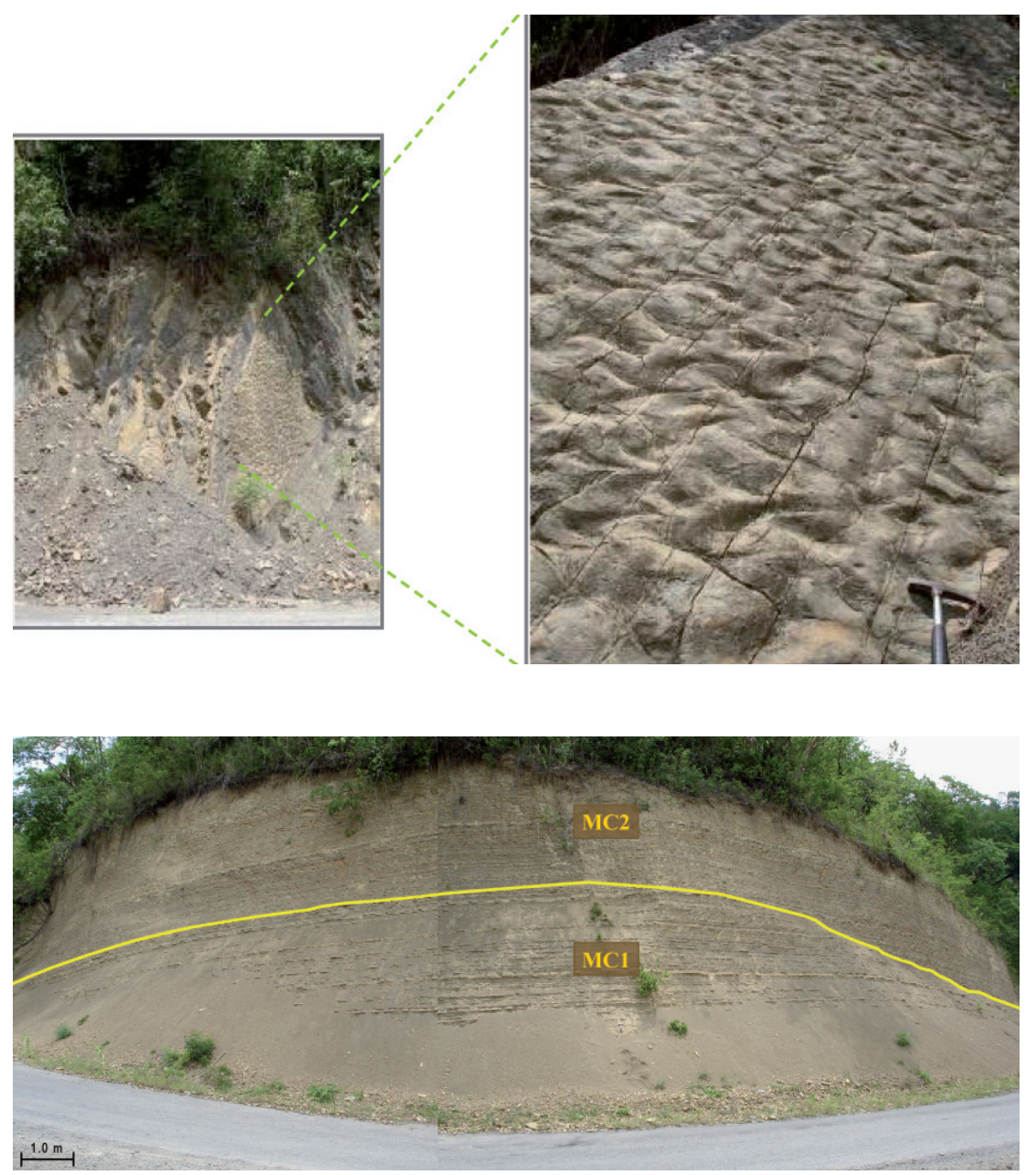

Foto 4.4. Superficies de estratificación onduladas como producto de compactación diferencial entre los estratos arenosos y arcillosos, formada durante su sepultamiento (martillo como escala: $31.8 \mathrm{~cm}$.)
Foto 5.1. Afloramiento de la Media Cuesta-Tlalaxo, en donde se observan los miembros MC1 y MC2 


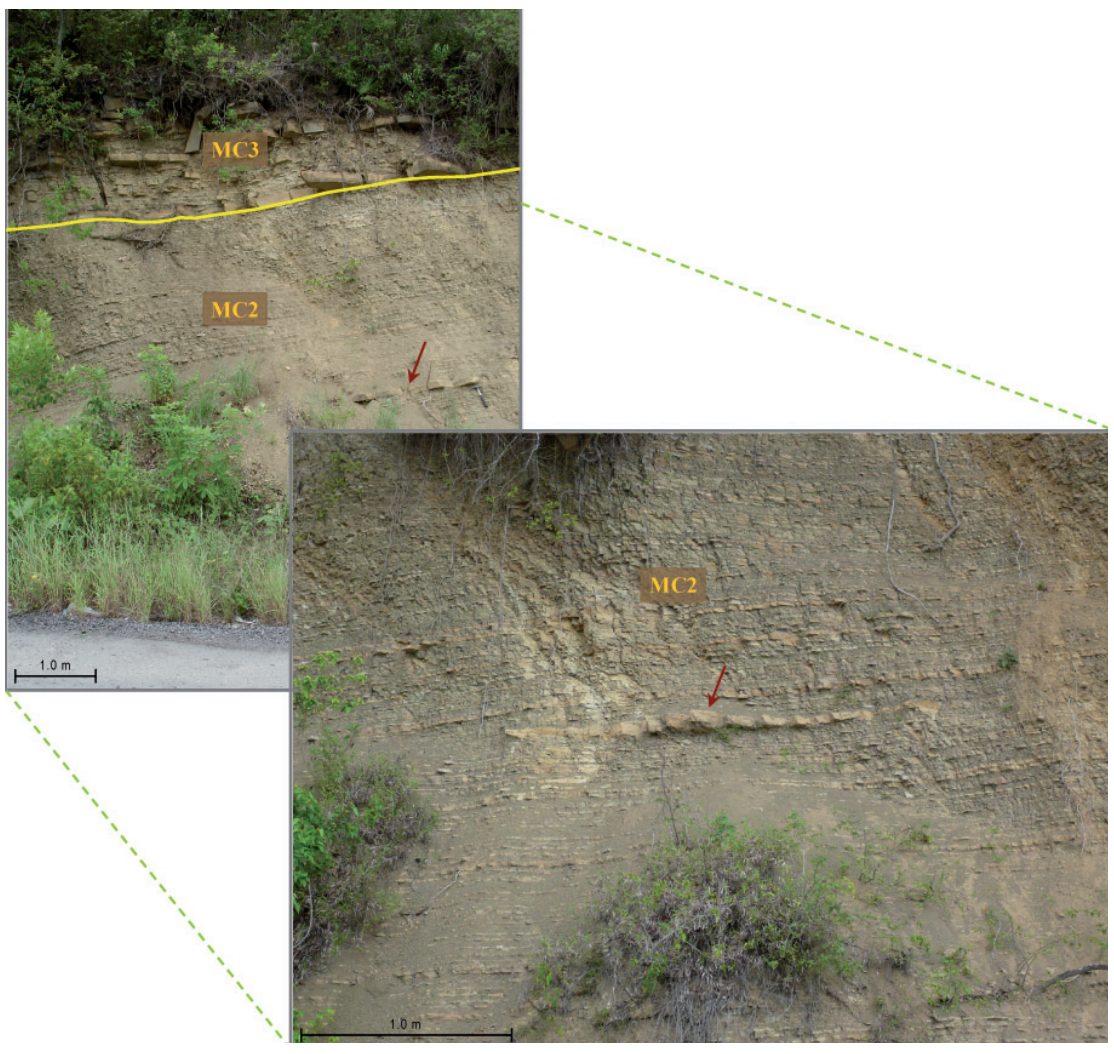

Foto 5.2. Afloramiento de la Media Cuesta-Tlalaxo, en donde se observan los miembros MC2 y MC3; nótese el horizonte canalizado en facies distales del abanico (señalado por la flecha)
Hacia la parte superior de la unidad estratigráfica dentro de la secuencia con estratificación delgada y de granulometría fina, se observan zonas canalizadas discretas, representadas por estratos de arenisca de grano medio de $10 \mathrm{~cm}$ de espesor por $2.10 \mathrm{~m}$ de ancho en promedio, los cuales corresponden a lentes lobulares dentro de la facie distal del abanico (foto 5.2).

En la base de algunos de los estratos de arenisca de grano medio, se observan escasas trazas de actividad orgánica, debidas a Fucusopsis angulata (repichnia), así como el molde de algunas marcas de corriente ("flute casts"), las cuales presentan una dirección preferencial de flujo hacia el $\mathrm{N} 30^{\circ} \mathrm{E}$.

\section{Miembro MC3}

Con un espesor medido de $1.53 \mathrm{~m}$, compuesto con interestratificaciones de areniscas de grano medio a fino con espesores cíclicos de 10 a $15 \mathrm{~cm}$ y de 20 a $25 \mathrm{~cm}$ algunos estratos son lobulares y lenticulares de cerca de $45 \mathrm{~cm}$ formadas por areniscas con estratificación delgada de 1 a $2 \mathrm{~cm}$ de espesor y limonitas-lutitas de entre 2 a $6 \mathrm{~cm}$ cada horizonte; en la base de algunos de los estratos de arenisca, se observan huellas de ichnofósiles (Fucusopsis angulata).
El ambiente de depósito de la parte basal de esta secuencia (miembros MC1 y MC2), corresponde a la facies D y G de lóbulo distal (Mutti et al., 1972); en donde predominan los sedimentos texturalmente finos transportados en suspensión por corrientes de bajo régimen de flujo y con canalizaciones terminales. Por sus características sedimentarias el miembro MC3 puede corresponder a facies $\mathrm{C}$ canalizadas en abanico medio; en donde se infiere que el depósito de los sedimentos se llevó a cabo por una serie de lóbulos progradantes.

\section{Sitio 6. Afloramiento "El Zapotillo"}

Rancho El Zapotillo, SLP de San Martín Chalchicuautla al noroeste $4 \mathrm{~km}$, rumbo al poblado de Tepemiche, SLP. Coordenadas: 14Q (538,247 m E, 2'365,618 m N).

En este afloramiento el espesor medido es de $5.20 \mathrm{~m}$ y el rumbo general de la secuencia estratigráfica es $\mathrm{N}$ $28^{\circ} \mathrm{W}, 06^{\circ} \mathrm{NE}$ (foto 6.1).

\section{Miembro ZAP1}

Esta unidad tiene un espesor medido de 3.08 m y está compuesta por intercalaciones de areniscas de grano medio a fino y limolitas-lutitas con estratificaciones del- 


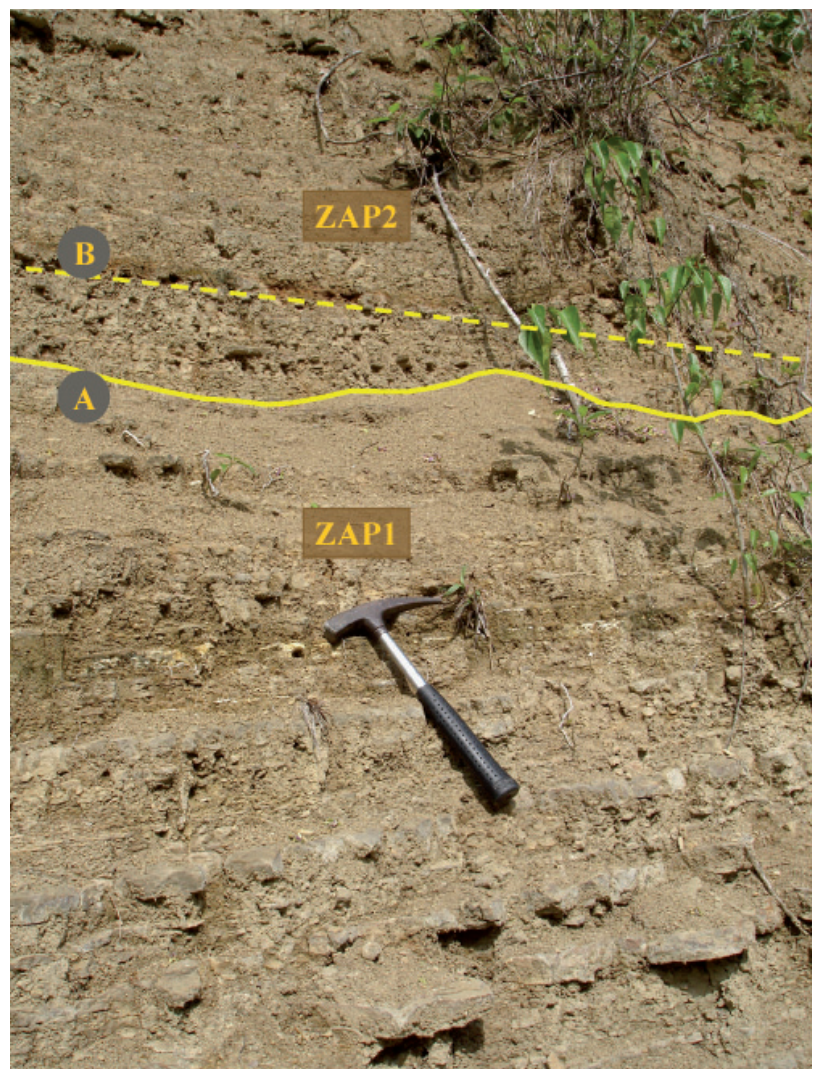

Foto 6.1. Afloramiento El Zapotillo, en donde se observan los miembros ZAP1 y ZAP2; nótese un microcanal en la transición de ambos miembros (A: base, B: cima) (martillo como escala: $31.8 \mathrm{~cm}$ )

gadas de 2 a $3 \mathrm{~cm}$, algunas capas varían entre 5 y $7 \mathrm{~cm}$; se observa la presencia de ichnofósiles sobre la superficie inferior de los estratos de areniscas, cuyas trazas pudieran corresponder a Megagrapton irregulare (?) (pascichnia), organismo característico de comunidades de aguas marinas profundas de al menos $500 \mathrm{~m}$ (Bitter, 1983).

\section{Miembro ZAP2}

Unidad estratigráfica de $2.12 \mathrm{~m}$ de espesor, caracterizada por intercalaciones predominantes de limolitas-lutitas con areniscas de grano fino; lo cual le da un carácter texturalmente más fino a esta parte de la secuencia. Los estratos individuales de arenisca tienen un espesor promedio de 1 a $2 \mathrm{~cm}$, observándose dos estratos de $6 \mathrm{~cm}$ de espesor con estructuras de corte y relleno como producto posible de un canal remanente (foto 6.1).

La secuencia estratigráfica se interpreta como abanico externo en su facies distal correspondiente a la facies D de Mutti et al. (1972); formado por corrientes turbidíticas de baja densidad.

\section{Conclusiones}

En los afloramientos estudiados del noroeste de la Cuenca de Chicontepec, se pueden reconocer las litofacies propuestas por Mutti et al. (1972): B, C, D, E y G, asociadas a zonas de transición lóbulo-canal y lóbulos por desbordamientos ("overbanks"), depositados en subambientes de abanico medio y externo.

Algunos de los depósitos sedimentarios formados por deslizamiento, derrumbe y flujo de escombros, presentan una dirección preferencial hacia el NE; en tanto que, los flujos turbidíticos, tabulares y lenticulares de los lóbulos submarinos, muestran una tendencia regional de transporte hacia el SE.

Las areniscas de la Formación Chicontepec son inmaduras, predominando los clastos líticos, de los cuales entre el $40 \%$ y el $88 \%$, corresponden a fragmentos de calizas y el resto a litarenitas feldespáticas y felsarenitas, lo que indica que el mayor aporte de sedimentos corresponde a detritos calcáreos provenientes de la Sierra Madre Oriental al occidente, de la Isla de Tuxpan al oriente y del Macizo de Teziutlán al sur.

El modelo que se conceptualiza en este trabajo sobre los mecanismos de transporte y sedimentación de los depósitos turbidíticos del Grupo Chicontepec (figura 3), es principalmente hipotético y esquematizado; por lo que es imperativo correlacionar cronoestratigráficamente la secuencia aflorante con la del subsuelo profundo, con el objetivo de contar con un mejor entendimiento integral sobre la distribución espacio-temporal de los depósitos turbidíticos y sus facies asociadas en la cuenca terciaria de Chicontepec.

\section{Referencias}

Aguayo C.J.E., Sandoval O.J.H., Araujo M.J. y Santillán P.N. Geología regional de la Cuenca de Chicontepec del centro-oriente de México, como antecedente para el estudio de su porción noroccidental en afloramiento. III Simposio: La investigación y desarrollo en la Facultad de Ingeniería 2006, UNAM. (Inédito).

Belt B.C. Stratigraphy of the Tampico District of Mexico.Bulletin American Association of Petroleum Geologist, 9(1):136-144. 1925.

Bitter M.R. Sedimentology and Petrology of the Chicontepec Formation, Tampico-Misantla Basin, Eastern Mexico. Thesis (Master of Science). B.S. University of Kansas, Geology. (unpublished). 1983.

Bitter M.R. Sedimentation and Provenance of Chicontepec Sandstones with Implications for Uplift of the Sierra Madre Oriental and Teziutlan Massif, East-Central Mexico, en: Pindell J.L., Perkins R.F. (eds.). Mesozoic and Early Cenozoic Development of the Gulf of Mexico and Caribbean Region: A Context for Hydrocarbon Exploration. Transactions, $13^{\text {th }}$ Annual Gulf 
Coast Section of Society for Sedimentary Geology (GCSSEPM). Research Conference, pp. 155-172. 1993.

Busch D.A., Govela A.S. Stratigraphy and Structure of Chicontepec Turbidites, Southeastern Tampico-Misantla Basin, Mexico. The American Association of Petroleum Geologist Bulletin, 62(2):235-246. 1978.

Contreras-Barrera A., Argáez-Gío R. Consideraciones paleobiológicas de los icnofósiles de la Formación Chicontepec en el estado de Puebla. Revista del Instituto de Geología, 6(1):73-85. 1985.

Dumble E.T. Geology of Northern end of the Tampico Embayment Area. California Academy of Sciences. Procceding, 8:113156. 1918,

Gamper M.A. Bioestratigrafía del Paleoceno y Eoceno de la Cuenca Tampico-Misantla basada en los foraminíferos planctónicos. Revista del Instituto de Geología, 1(2):117-128. 1977.

Google-Imágenes. TerraMetrics, datos de mapa 2009, Tele Atlas. 2009.

López-Ramos E. Geología de México. Tomo II. 2da. edición. México DF. 1979. 454 p.

Muir J.M. Geology of the Tampico Region. Bulletin of the American Association of Petroleum Geologist, Tulsa, Oklahoma, USA, 280 p. 1936.

Mutti E., Normark W.R. Comparation Examples of Modern and Ancient Turbidite Systems: Problems and Concepts, en: Legget J.K., Zuffa G.G. Marine Clastic Sedimentology. Concepts and Case Studies. Ghaharn and Trotan. 1987. Pp. 1-38.

Mutti E., Normark W.R. An Integrate Approach to the Study of Turbidite Systems, en: Weimer P., Link H. (eds.). Seismic Facies and Sedimentary Processes of Submarine Fans of Turbidite Systems, Springer-Verlag. 1991. Pp. 75-106.

Mutti E., Ricci-Lucci F. Le Torbiditi dell' Apennine Settentrionale: Introduzione all'Analisi di Facies. Memorie Societa Geologica Italiana, Vol. 11, pp. 161-199 (Traducido al inglés por Nilsen T.H., 1978). International Geology Review, 20(2):125166. 1972.
Nájera H. Estudio de las formaciones del Eoceno en la región de Poza-Rica. Boletín de la Asociación Mexicana de Geólogos Petroleros, 4(3-4):71-115. 1952.

Normark W.R. Deep Water fan System, en: Mayoon L.B. The Petroleum System Status of Research and Methods. U.S. Geological Survey, Menio Park Calif. 1990. Pp. 20-24.

Normark W.R., Posamentier H. y Mutti E. Turbidite Systems: State of the Art and Future Directions. Reviews of Geophysics, 31(2):91-116, May 1993.

Ortega G.F., Mitre S.L.M., Roldán Q.J., Aranda G.J.J., Morán Z.D., Alaniz A.S.A. y Nieto S.Á.F. Carta geológica de la República Mexicana. $5^{\text {a }}$ ed. Universidad Nacional Autónoma de México. Instituto de Geología y Secretaría de Energía, Minas e Industria Paraestatal. Consejo de Recursos Minerales, mapa con texto explicativo, escala 1:2'000,000, 74 p. 1992.

Ricci-Lucchi F. Depositional Cycles in Two Turbidite Formations of Northern Apennines (Italy). Journal Sedimentary Petrology, 45:3-43. 1975.

Santillán P.N. Paleoambientes sedimentarios en facies turbidíticas en la Cuenca Terciaria de Chicontepec, Centro-Oriente de México. Tesis (Maestría en Ciencias). Universidad Nacional Autónoma de México. (Inédita). 2009. 103 p.

Santillán P.N. y Aguayo C.J.E. Caracterización e interpretación de facies turbidíticas en el NW de la Cuenca Paleógena de Chicontepec, centro-oriente de México. Informe Técnico de la Facultad de Ingeniería, UNAM. 38 p. (Inédito). 2009.

Schlumberger (Publ.). Evaluación de formaciones en México. Cap. 2. Explotación petrolera en México. Pp. II-15. 1984.

Servicio Geológico Mexicano-B- $\left(\mathrm{SGM}^{*}\right)$ [en línea]. Léxico estratigráfico de México. 2007. Disponible en: http://www.coremisgm.gob.mx/inicio.html

Vail P.R., Audemaro F., Bouman S.A., Eisner P.N., Pérez C.G. The Stratigraphic Signatures of Tectonics Eustasy and Sedimentology and Overview, en: Einsele G., Reikan W., Seilacher A. (eds.). Cycles and Events in Stratigraphy. Springer-Verlang (Publ.). 1991. Pp. 617-659.

\section{Semblanza de los autores}

Noé Santillán-Piña. Ingeniero geólogo y maestro en ciencias geológicas por la Universidad Nacional Autónoma de México. Actualmente es técnico académico titular A de tiempo completo definitivo en la División de Ingeniería en Ciencias de la Tierra de la Facultad de Ingeniería de la Universidad Nacional Autónoma de México.

Joaquín Eduardo Aguayo-Camargo. Ingeniero geólogo por la Facultad de Ingeniería de la Universidad Nacional Autónoma de México. Obtuvo la maestría en la Universidad Baylor en Texas y el doctorado en ciencias geológicas en la Universidad de Texas, Dallas. Actualmente es investigador titular $C$ de tiempo completo y profesor en la División de Ingeniería en Ciencias de la Tierra de la Facultad de Ingeniería de la Universidad Nacional Autónoma de México. 